\title{
Development of a Tool to Assess In-Situ Curing of Foamed Bitumen
} Mixtures \\ Kranthi Kuna ${ }^{1}$, Gordon Airey ${ }^{2}$, Nick Thom ${ }^{3}$ \\ ( ${ }^{a}$ Researcher, University of Nottingham, the United Kingdom, k.kranthi13@gmail.com) \\ $\left({ }^{\mathrm{b}}\right.$ Professor, University of Nottingham, the United Kingdom, \\ gordon.airey@nottingham.ac.uk) \\ ( ${ }^{\mathrm{A} A s s i s t a n t}$ Professor, University of Nottingham, the United Kingdom, \\ nicholas.thom@nottingham.ac.uk)
}

\begin{abstract}
This paper discusses the simplest yet crucial mix design consideration of Foamed

14 understanding of the curing mechanism of FBMs and lessen the gap between

15 laboratory curing and field evolution of these mixtures. This was achieved by carrying

16 out a laboratory curing study in two phases. The first phase aimed to understand the

17 curing mechanism and to interpret the level of impact of factors such as temperature

18 and time on the curing of FBMs. The effect of these factors on curing was evaluated

19 with reference to stiffness gain and water loss of FBM specimens. The second phase

20 was intended to develop a tool to assess in-situ curing of FBMs. With a view to

21 assessing in-situ strength (or stiffness) the applicability of the maturity method, which

22 is commonly used to estimate in-situ compressive strength of concrete before removal

23 of formwork, to FBMs was evaluated. A strong correlation was found between

24 maturity and the stiffness values obtained from the laboratory tests which resulted in

25 development of maturity-stiffness relationships. The application of the method to

26 assess the in-situ stiffness was presented using three hypothetical pavement sections.

27 The results illustrate the influence of ambient temperature and the importance of

28 cement addition to FBMs.
\end{abstract}

29

30

31

32

Keywords: Foamed bitumen mixes, curing, mechanical properties, maturity, insitu stiffness 
3 Curing is the process by which FBMs gain strength or stiffness with expulsion

4 of water. Despite the fact that a wide range of studies have been undertaken on curing,

5 significant issues still need to be addressed. This is because of the complexity that

6 water brings to these mixtures. Water plays different roles during different stages of

7 mix design. Its existence aids the mixing and compaction phases, but negatively

8 affects the early strength. In addition to the climatic parameters like temperature,

9 humidity and wind, other factors such as aggregate gradation and properties, layer

10 thickness, initial water, binder, cement (or) additive content, layers applied on top,

drainage condition, and finally traffic load influence the curing process [1].

Assessing the in-situ curing of FBM is essential to decide when the next layer of the pavement is to be applied. It also helps to obtain in-situ stiffness modulus of the pavement layers which is the most important input parameter in pavement design and evaluation. However, this assessment is not practical using non-destructive testing equipment such as falling weight deflectometers (FWDs) and light weight deflectometers (LWDs) particularly during the construction (early stages of curing). Moreover, obtaining cores from the FBM layer is also difficult especially in the initial phase of the curing [2]. Hence, Lee [3] highlighted the importance of specifying curing condition in terms of amount of water present in the mixture. Since then different agencies have specified maximum water content in the mixtures as a requirement of a cold recycled layer (both foamed bitumen and emulsion treated). The departments of transportation of Arizona, Iowa, South Dakota, Vermont and Washington allow a maximum water content of $1.5 \%$ before a layer is laid over an FBM layer [4]. In Europe the usual range for residual water content to determine the ideal time for placing a bituminous layer over FBM layer is 1-1.5\% [5]. To evaluate this in the field, a link is necessary between laboratory curing and in-situ curing. To achieve this it is important to understand the curing mechanism and factors that affect curing such as temperature, time and material content (RAP, cement, etc.) and the level of the extent to which these factors affect the curing mechanism.

The present work has tried to address some of the above discussed concerns by identifying important parameters that affect curing and establishing a necessary link between laboratory and in-situ curing. In order to assess in-situ strength (or stiffness) the applicability of the maturity method, which is commonly used to estimate in-situ compressive strength of concrete before removal of formwork, was applied and evaluated with regard to FBMs.

\section{METHODOLOGY ADOPTED}

To achieve the above mentioned objectives a curing study was conducted in two phases. In the first phase (Phase 1) an experimental study was carried out to interpret the level of impact that temperature and time have on the curing of FBMs. The effect of these factors on curing has been evaluated with reference to stiffness gain and water loss of specimens made from these mixtures. The second phase (Phase 2) deals with the applicability of the maturity method as a tool to assess the in-situ characteristics of FBMs. Along with validating the maturity method, practical implications of the maturity method were also evaluated in Phase 2.

In the present study, the terms 'early stage curing' (less than 7 days after compaction); 'intermediate stage curing' (between 8 days and 35 days) and 'long term 
curing' (between 35 days and 300 days) were used for convenience. In Phase 1 FBMs were cured up to $30-35$ days at different curing temperatures and the curing trends were developed by monitoring water loss and stiffness gain in FBMs over this period of time. In Phase 2 the specimens were cured long term i.e. up to 180 to 300 days and maturity - stiffness models were developed. Table 1 presents the mixtures considered in the study. As can be seen from the table a total of four mixture types were considered in the study; two with 50\% Reclaimed Asphalt Pavement (RAP) aggregate and two without any RAP content. One from each category contained 1\% cement as can be seen in the table. The table also presents the mix design parameters that were adopted in the study. These are the parameters that were obtained from the mix design study carried out on these mixtures without cement [6]. It was assumed that the addition of cement doesn't influence the optimum mixing water content (MWC), foamed bitumen content $(\mathrm{FBC})$ and design number of gyrations $\left(\mathrm{N}_{\text {design }}\right)$ in the gyratory compactor. Therefore, the same parameters that were obtained in the study for the mixtures without cement were used for the mixtures with cement ( $1 \%$ cement content). The cement used in the study is Ordinary Portland Cement (OPC). For brevity the physical properties of the materials used in the study are not presented in the paper. The details can be found elsewhere [6]. Although the original curing study includes all the mixtures in Table 1, only results of mixtures with $100 \%$ virgin aggregate (100\%VA) are discussed in the curing parametric study (Phase 1) of the present paper.

Table 1 Mix design parameters adopted in the study

\begin{tabular}{|c|c|c|c|}
\hline & MWC (\%) & FBC (\%) & N $_{\text {design }}$ \\
\hline 50\%RAP+1\%Cement & 4.8 & 3.25 & 110 \\
\hline 50\%RAP & 4.8 & 3.25 & 110 \\
\hline 100\%VA+1\%Cement & 5.2 & 4 & 140 \\
\hline 100\%VA & 5.2 & 4 & 140 \\
\hline
\end{tabular}

Notes: RAP: Reclaimed Asphalt Pavement; VA: Virgin Aggregate; MWC: Mixing Water Content;

FBC: Foamed Bitumen Content; $\mathrm{N}_{\text {design }}$ : design number of gyrations

\section{CURING MECHANISM (PARAMETRIC) STUDY}

As discussed previously, since most of the agencies require a limit on the amount of water present in the FBM layer before laying a binder course and (or) surface, a link is necessary between laboratory curing and field water content requirements. Therefore, the present study aimed at developing curing trends in terms of water loss and stiffness gain for different temperatures and over a period of time to understand the curing mechanism which also helps in establishing a link between laboratory curing and field curing. These trends also help in understanding the acceleration of curing at elevated temperatures and to predict the properties of the FBM layers in the pavement for different climatic conditions. The water evolution trends obtained by monitoring the curing process give knowledge on the time it takes for various materials to reach equilibrium water content [1]. The results are also expected to be valuable inputs to formulate the necessary relation between laboratory properties and field trends, which gives valuable guidance for structural design of pavements.

\subsection{Selection of conditioning temperatures}

A detailed literature review revealed that conditioning temperatures of $60^{\circ} \mathrm{C}$, $40^{\circ} \mathrm{C}$ and $20^{\circ} \mathrm{C}$ have been popular, although other conditioning temperatures can also 
be found in the literature. Curing temperatures above the softening point are usually recommended to be avoided as they may cause bitumen to flow and change its dispersion within the mixture which may change mixture properties in addition to inducing unrepresentative ageing of the bitumen. Therefore, to keep the specimens below the softening point of the bitumen used in the mixture, which is $45^{\circ} \mathrm{C}$ for the $70 / 100$ grade bitumen used in this study, curing temperatures of $40^{\circ} \mathrm{C}, 30^{\circ} \mathrm{C}, 20^{\circ} \mathrm{C}$ and $5^{\circ} \mathrm{C}$ were adopted. Though curing at $20^{\circ} \mathrm{C}$ and $5^{\circ} \mathrm{C}$ are not always to be considered as accelerated curing, these temperatures were included in the study to understand the effect of these temperatures on curing.

\subsection{Monitoring curing}

The curing trends were developed by monitoring water loss and stiffness gain in FBMs over a period of time. The specimens were gyratory compacted cylindrical specimens of $100 \mathrm{~mm}$ diameter and about $62 \mathrm{~mm}$ high. The extracted specimens were placed in temperature controlled cabinets at the curing temperature. The nondestructive stiffness test, Indirect Tensile Stiffness Modulus (ITSM), was selected for assessing curing of the FBM specimen over a period of 30 days. This test was preferred over ultrasonic testing because of its more realistic level of applied stress. It was carried out in accordance with DD 213: 1993. ITSM was chosen in order to carry out the test on the same set of specimens to nullify variability in the mixtures and to derive reliable trends for curing evaluation. These tests were carried out at a temperature of $20^{\circ} \mathrm{C}$.

It was identified from preliminary studies [7] that the mechanical properties of sealed specimens (likely to be most representative of in-situ conditions) were always found to be 50-70\% of those of unsealed specimens. So it was assumed that the sealed condition can be interpreted using unsealed data and therefore only the unsealed curing condition was considered in the present study.

\subsection{Effect of time and temperature on curing trends}

The water content in the $100 \%$ VA-FBM specimens which was monitored over time is plotted in Figure 1. Trend lines which are power curves are also included in the figure. The initial water content in the mixture during compaction was $5.2 \%$. The plots showed that water content in the specimen reached about a quarter (approximately $1.3 \%$ ) of the initial amount after 24 hours of curing at both $30^{\circ} \mathrm{C}$ and $40^{\circ} \mathrm{C}$. Similarly, water content reached about half $(2.6 \%)$ of the initial amount when specimens were cured at $20^{\circ} \mathrm{C}$ and $5^{\circ} \mathrm{C}$. The trends suggest that the rate of water loss is approximately proportional to the amount of water present in the mixture. In other words, the rate of water loss decreased with time. It is clear from the plots that the water loss is dependent on the curing temperature. The higher the curing temperature the faster was the water loss. However, all curves, except the $5^{\circ} \mathrm{C}$ curve, seem to reach a steady state after which the loss is negligible.

The stiffness (ITSM) values that were measured over time on the 100\% VAFBM specimens cured at different temperatures are plotted in Figure 2. The plot shows stiffness monitored for a period of 30 days at curing temperatures of $40^{\circ} \mathrm{C}, 30^{\circ} \mathrm{C}, 20^{\circ} \mathrm{C}$ and $5^{\circ} \mathrm{C}$. Trend lines which are logarithmic with positive tangential slope are also included in the plot. As can be seen from the figure, for all conditions stiffness increased with time of curing. However, this gain was more rapid for specimens cured at higher temperatures. This could be attributed to rapid water loss that takes place at higher temperature which yields higher stiffness values with time. Moreover, in a similar way to water loss, the rate of stiffness gain is decreasing with time which implies that the stiffness gain is very much related to water loss from the specimen. 
1 This curing phenomenon can be seen in Figure 3 in which water loss and stiffness gain 2 of $100 \%$ VA-FBM specimens cured at $20^{\circ} \mathrm{C}$ is presented. The figure illustrates the 3 curing mechanism in which these FBMs gain stiffness with water loss during curing.

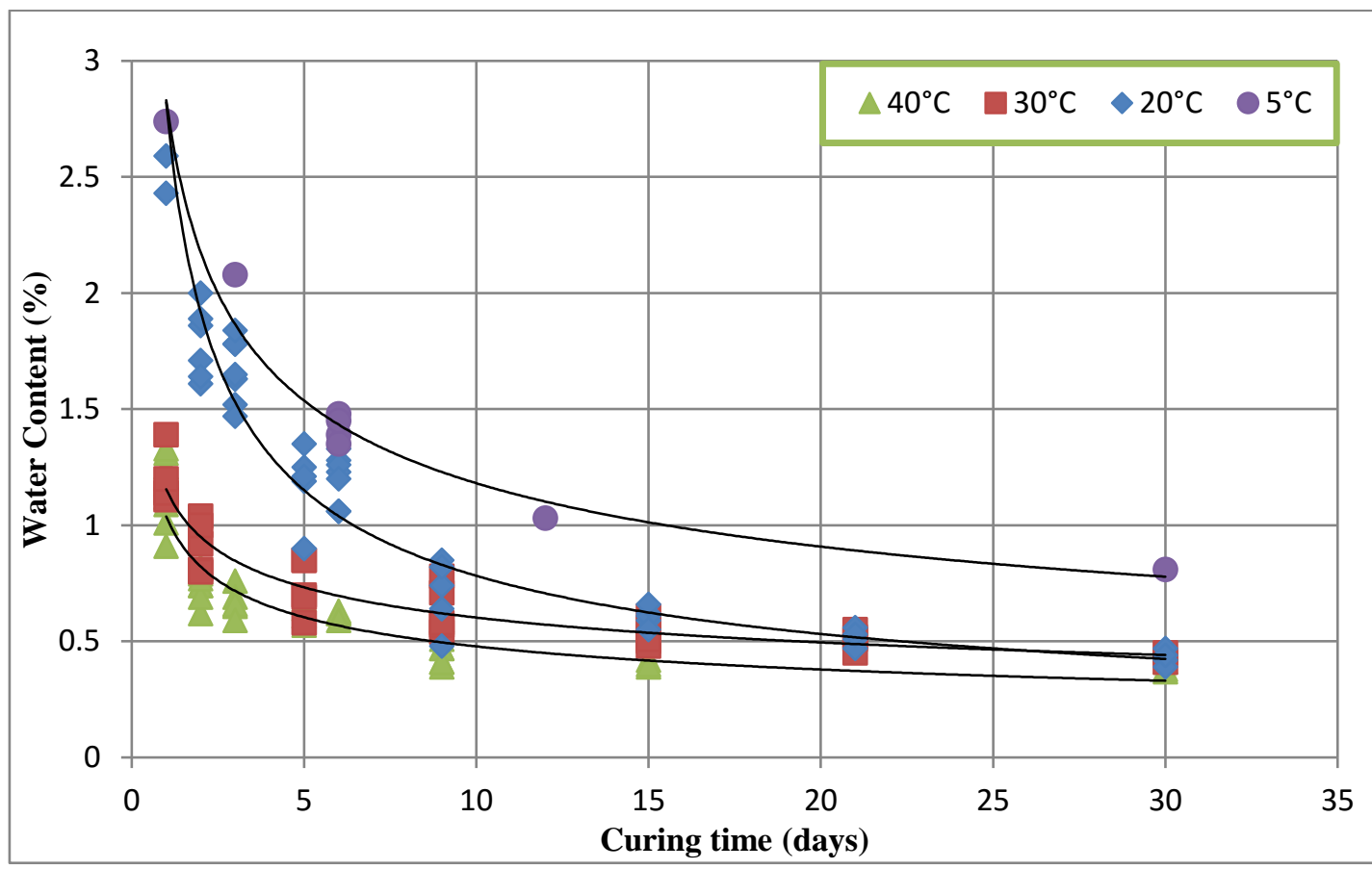

6 Figure 1 Effect of time and temperature on water loss in 100\% VA-FBM 7 specimens

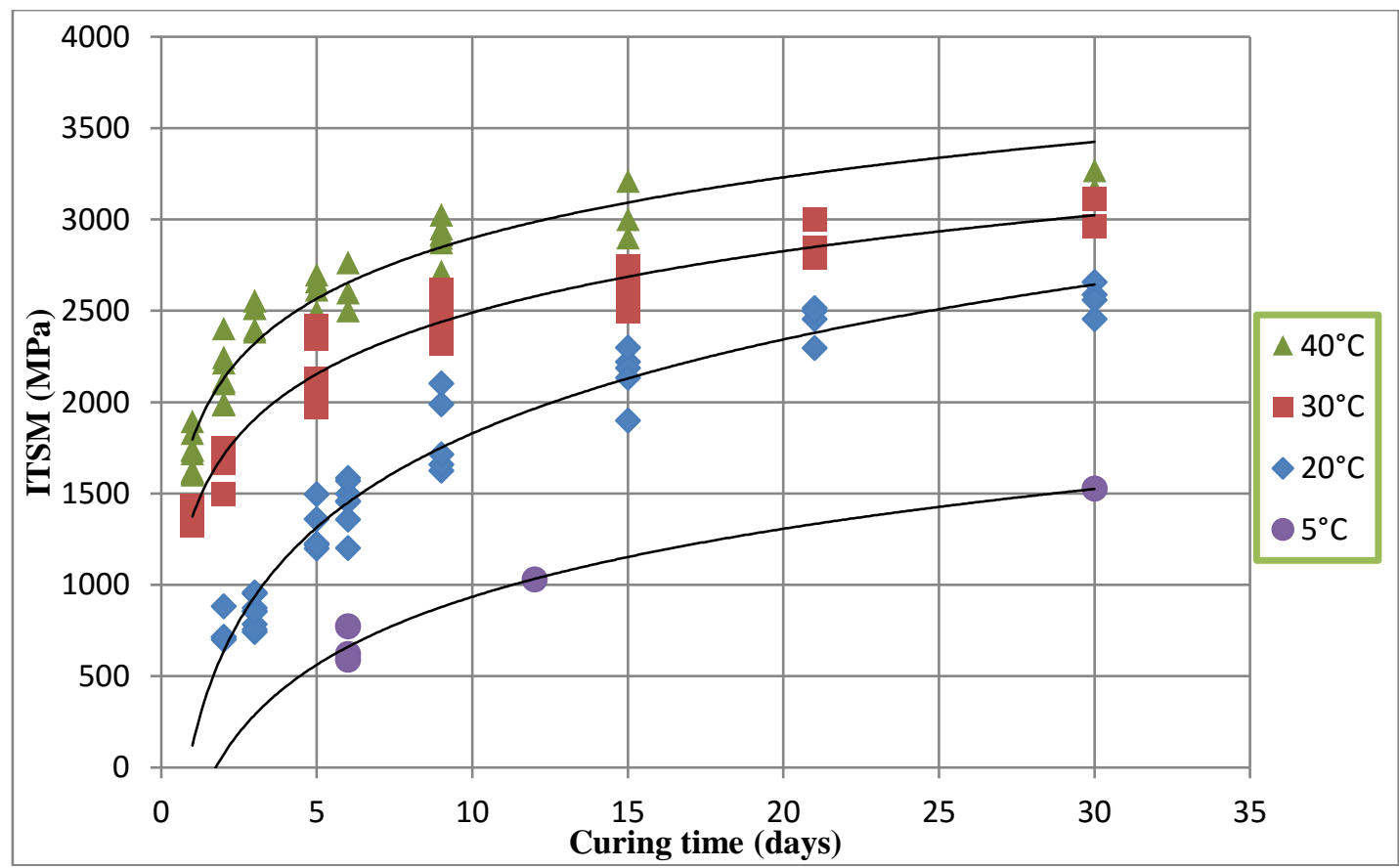

8 Figure 2 Effect of time and temperature on stiffness gain in $100 \%$ VA-FBM specimens 


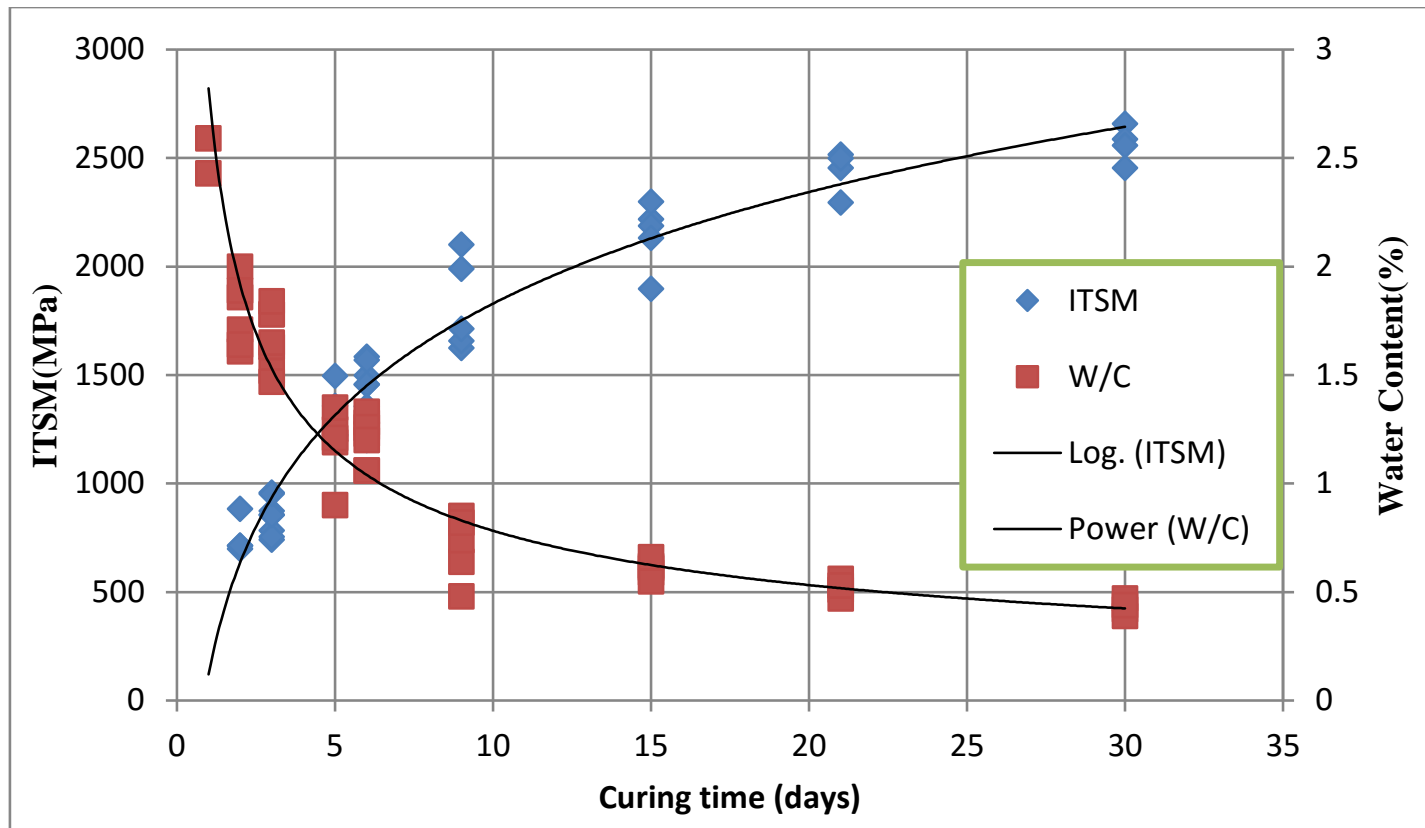

Figure 3 Effect of time on curing (water loss and stiffness gain) in 100\% VA-FBM cured at $20^{\circ} \mathrm{C}$

\subsection{Effect of water content on stiffness}

Figure 4 shows a plot of stiffness (ITSM) versus water content for the $100 \%$ VA-FBM specimens that were cured at different temperatures. As a general trend, with decrease in the water content the stiffness increased. However, as can be seen from the figure when individual temperatures are considered it is found that the temperature has a significant additional impact on the stiffness of the mixture. For example, the specimens which were cured at $40^{\circ} \mathrm{C}$ having water content around $1 \%$ showed far higher stiffness (ITSM) than the specimens cured at lower temperatures at the same water content.

To study the effect of temperature on bitumen properties, bitumen was extracted in accordance with BS 598-102 from the 100\% VA-FBM specimens that were cured for 30 days. Frequency sweep tests were carried out on the extracted bitumen and complex modulus $\left(\mathrm{G}^{*}\right)$ master curves are plotted in Figure 5 to understand the effect of the curing temperature on the bitumen properties. The figure presents the complex modulus $\left(\mathrm{G}^{*}\right)$ master curves at a reference temperature of $20^{\circ} \mathrm{C}$ for the extracted bitumen from $100 \%$ VA-FBM specimens cured at $20^{\circ} \mathrm{C}$ and $40^{\circ} \mathrm{C}$ for 30 days. It has to be noted that the change in bitumen complex modulus before foaming and after extraction is not only because of the curing but also because of oxidation that occurs during bitumen foaming. As can be seen from the plots, the difference in complex modulus for the extracted bitumen is significant, particularly at the ITSM testing frequency which is approximately $5 \mathrm{~Hz}$ which indicates that the difference in bitumen ageing between $20^{\circ} \mathrm{C}$ and $40^{\circ} \mathrm{C}$ curing is considerable. Hence, from the results it is evident that water loss is not the only mechanism involved in the curing. High temperature is clearly responsible for additional stiffness gain, possibly by facilitating binder adhesion and more importantly because of the increase in binder stiffness during the curing process.

31 The practical implication of these observations is that specifying a water content
32 limit for FBM layers before allowing traffic or allowing layers (binder courses) to be 
1 placed over the FBM layer is not appropriate. For example if an agency specified a $21 \%$ water content limit, the $100 \%$ VA mixture takes approximately 2 days, 7 days and 315 days respectively if the average temperature is $40^{\circ} \mathrm{C}, 20^{\circ} \mathrm{C}$ and $5^{\circ} \mathrm{C}$ (Figure 1). 4 However, it reaches different levels of stiffness. In this example it reaches $1850 \mathrm{MPa}$ 5 at $40^{\circ} \mathrm{C}, 1450 \mathrm{MPa}$ at $20^{\circ} \mathrm{C}$ and $1150 \mathrm{MPa}$ at $5^{\circ} \mathrm{C}$ (Figure 4 ). The stiffness achieved by 6 the mixture at $40^{\circ} \mathrm{C}$ is about $60 \%$ higher than that achieved at $5^{\circ} \mathrm{C}$ for the same water 7 content. This issue can be addressed by developing a tool to assess the stiffness of 8 these mixtures based on the temperature history of the compacted FBM layer. The 9 following section discusses the development of such a tool.

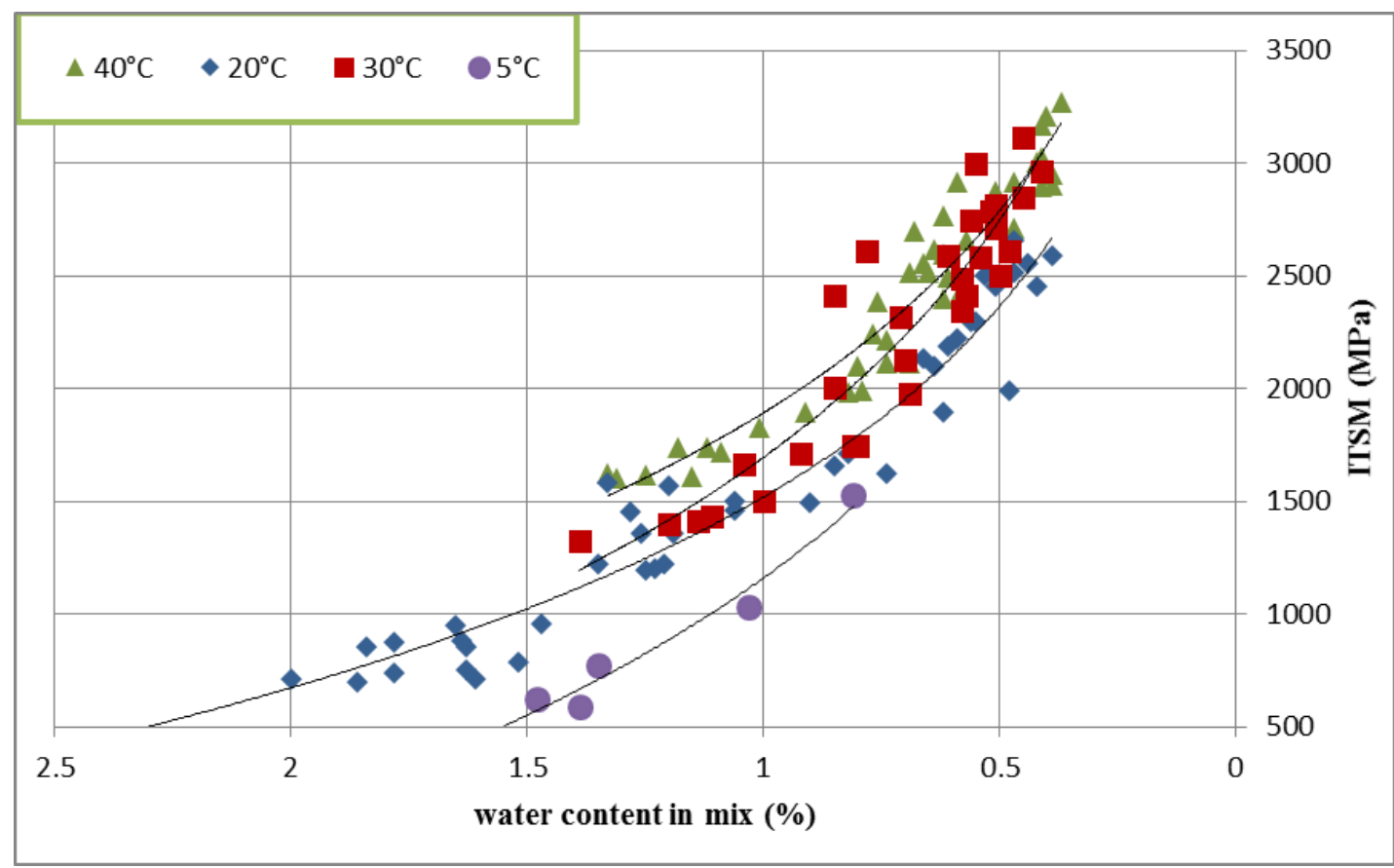




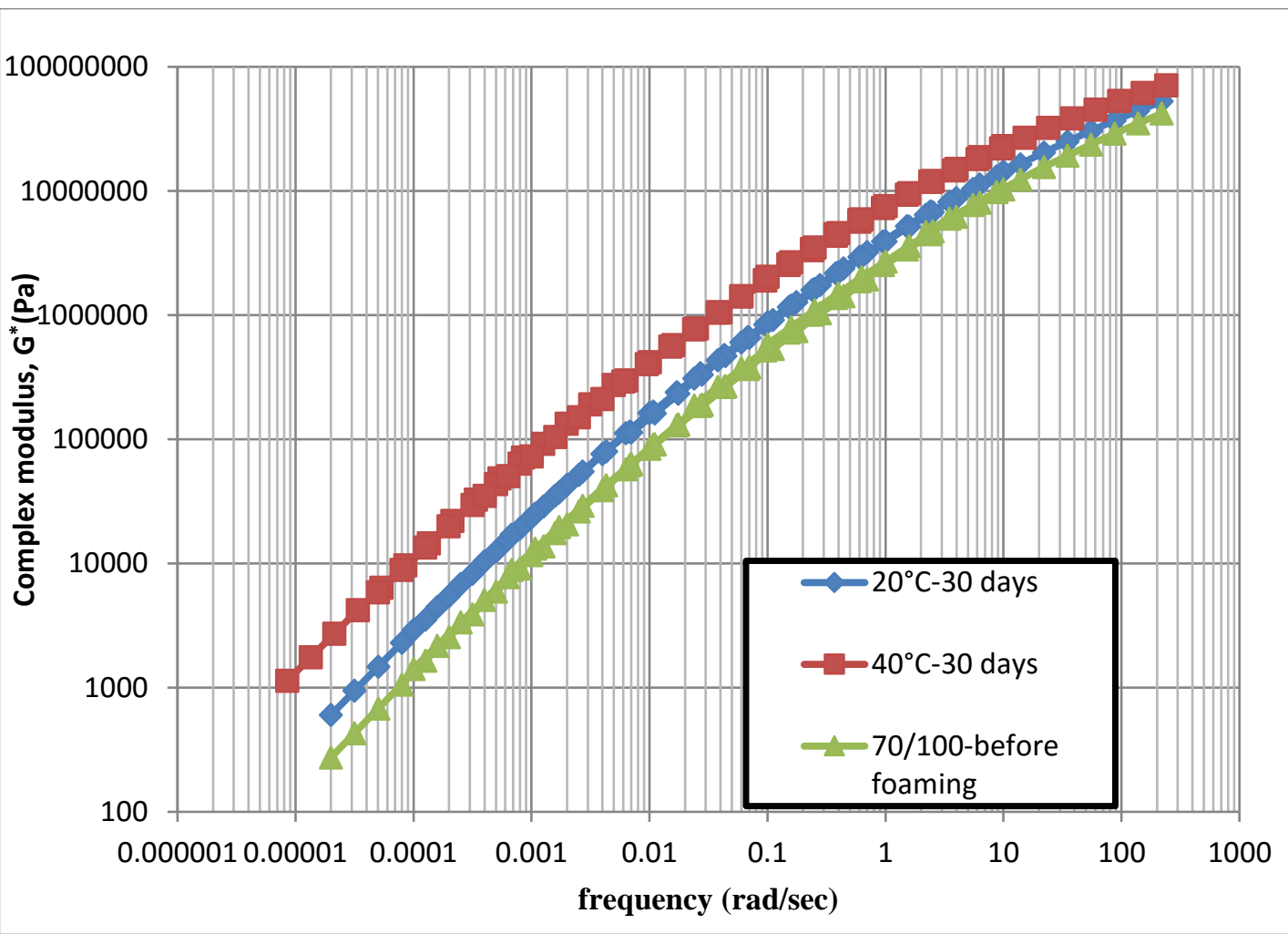

Figure 5 Effect of curing temperature on bitumen properties in terms of complex modulus master curves for extracted and pure bitumen at a reference temperature of $20^{\circ} \mathrm{C}$

\section{ASSESSMENT OF IN-SITU CURING}

Simulating in-situ condition in the laboratory is the most difficult step in mix design of cold recycled mixtures (FBMs and emulsion treated mixtures) [8]. Hence, a significant amount of research has been carried out on the development of a laboratory curing protocol for these mixes. However, there is a considerable variation in equivalent in-situ condition proposed by different researchers [9]. Nevertheless, as a general trend, with increase in conditioning time and temperature equivalent in-situ conditioning time is increased. In addition to that, the temperature was found to be a more influential parameter than water content on the mechanical properties. This observation suggests the use of the maturity method, which is used for estimating inplace strength of concrete based on its temperature history. The maturity method could help as a tool to estimate in-situ stiffness in view of the fact that the in-situ water content specification could result in different stiffness values for different temperature histories.

For concrete, the maturity method allows an estimation of in-situ compressive strength as the concrete design criterion in most cases is compressive strength. However as the objective of the present study is to propose a tool to estimate in-situ stiffness, which is an important input parameter for pavement structural design, stiffness (ITSM) was used to generate maturity - stiffness relationships.

\subsection{Maturity methods}

The maturity method is a technique commonly used in the concrete industry to account for the combined effects of time and temperature on the strength gain [10]. This technique allows in-place concrete strength to be estimated using time and 
temperature history of concrete in the field [11]. Maturity functions are used to convert the actual temperature to an equivalent temperature. This concept of a time temperature factor (maturity) can also be used to quantify the strength development of FBMs [12]. For instance, if FBM is cured say either at $40^{\circ} \mathrm{C}$ or $60^{\circ} \mathrm{C}$, the maturity can be calculated and the strength of the FBM can be estimated. If curing temperature is low (say $40^{\circ} \mathrm{C}$ ) the time to reach the required maturity will be longer than if the curing temperature is high $\left(\right.$ say $60^{\circ} \mathrm{C}$ ). As long as the same maturity is reached for both curing conditions, their strength should be the same.

\subsubsection{Selection of Maturity function}

The time-temperature functions (TTF) or maturity functions are used to convert time and temperature history of in-place concrete to a factor which is related to its strength. The two TTFs that are being used in in-place strength determination of concrete are the Nurse-Saul function and Arrhenius function.

As Malhotra and Carino (2003) [13] observed, in 1951 Saul defined maturity as the product of time and temperature based on his study on steam curing of concrete. Thus, maturity can be computed from the temperature history using the following equation called the Nurse-Saul equation (Eq. 1)).

$\mathrm{M}=\sum_{0}^{t}\left(T-T_{0}\right) \Delta t$

Equation 1

Where, $\mathrm{M}=$ maturity at age $\mathrm{t}, \mathrm{T}=$ average temperature of the concrete during the time interval $\Delta \mathrm{t}, \mathrm{T}_{0}=$ datum temperature

The Nurse-Saul function can be used to convert a given temperature time curing history to an equivalent age of curing at a reference temperature as follows:

$$
\boldsymbol{t}_{\boldsymbol{e}}=\frac{\sum\left(\boldsymbol{T}-\boldsymbol{T}_{0}\right)}{\left(\boldsymbol{T}_{r}-\boldsymbol{T}_{0}\right)} \Delta \mathbf{t}
$$

Equation 2

Where, $t_{\mathrm{e}}=$ equivalent age at the reference temperature, $\mathrm{T}_{\mathrm{r}}=$ reference temperature

In this case equivalent age represents the duration of the curing period at the reference temperature that would result in the same maturity as the curing period at the actual temperature. The above equation can be re-written as follows:

$$
t_{e}=\sum_{0}^{t} \alpha \Delta t
$$

Equation 3

Where, $\alpha=$ age conversion factor.

The age conversion factor converts a curing interval $\Delta \mathrm{t}$ to the equivalent curing interval at a standard reference temperature. For example if we assume a datum temperature of $0^{\circ} \mathrm{C}$ and reference temperature of $20^{\circ} \mathrm{C}$, then the age conversion factor for a specimen cured at $40^{\circ} \mathrm{C}$ for 3 days according to Eq. $2 \& 3$ is $3((40-0) /(20-0))$ and the equivalent age, $\mathrm{t}_{\mathrm{e}}$ is 6 days.

It has to be noted that Eq. 1 assumes a linear relationship between rate of strength gain and curing temperature. However this was not true in most cases [10]. Therefore later in 1977, [14], Hansen and Pedersen proposed a new time temperature function based on the Arrhenius equation. The new function allowed the computation of the equivalent age of concrete as follows:

$$
\boldsymbol{t}_{e}=\sum_{0}^{\mathrm{t}} \mathrm{e}^{\frac{-\mathrm{E}\left[\frac{1}{\mathrm{~T}}-\frac{1}{\mathrm{~T}_{\mathrm{r}}}\right]}{\mathrm{R}}} \Delta \mathrm{t}
$$

Equation 4

Where, $t_{e}=$ the equivalent age at the reference temperature, $E=$ apparent activation energy, $\mathrm{J} / \mathrm{mol}, R=$ universal gas constant, $8.314 \mathrm{~J} / \mathrm{mol}-\mathrm{K}, T=$ average absolute temperature of the concrete during interval $\Delta t$ in Kelvin, and $T_{r}=$ absolute reference temperature in Kelvin.

Carino (2001) [10], suggested that obtaining accurate values for activation energy is not practical and proposed a simplified equation (Eq. 5). It was also shown that both the equations (Eq. 4 and Eq. 5) give the same strength values from maturity 
- strength models. Moreover it was also stated that the sensitivity factor in Eq. 5 has

2 a more physical significance compared to activation energy. In the present study Eq.

35 is used for its simplicity.

Then the expression for the age conversion factor becomes the following: $\alpha=e^{B\left(T-T_{r}\right)}$

Equation 6

Where, $B=$ temperature sensitivity factor, $1 /{ }^{\circ} \mathrm{C}$

Figure 6 illustrates the importance of equivalent age and the summation involved

in Eq. 5. The figure describes a situation in which the FBM curing condition was changed to $20^{\circ} \mathrm{C}$ after curing for 40 days at $5^{\circ} \mathrm{C}$. As discussed earlier (Figure 2), the rate of stiffness gain is dependent on the stiffness achieved by the mixture. Therefore the equivalent age term considers this effect and adjusts the stiffness increase to the rate associated with the new conditioning temperature and the current stiffness. To explain graphically, when the curing condition changed from $5^{\circ} \mathrm{C}$ to $20^{\circ} \mathrm{C}$ on the $40^{\text {th }}$ day, the stiffness gain rate was taken from a horizontally transferred $20^{\circ} \mathrm{C}$ curve rather than the rate of the actual $20^{\circ} \mathrm{C}$ curing curve on the $40^{\text {th }}$ day.

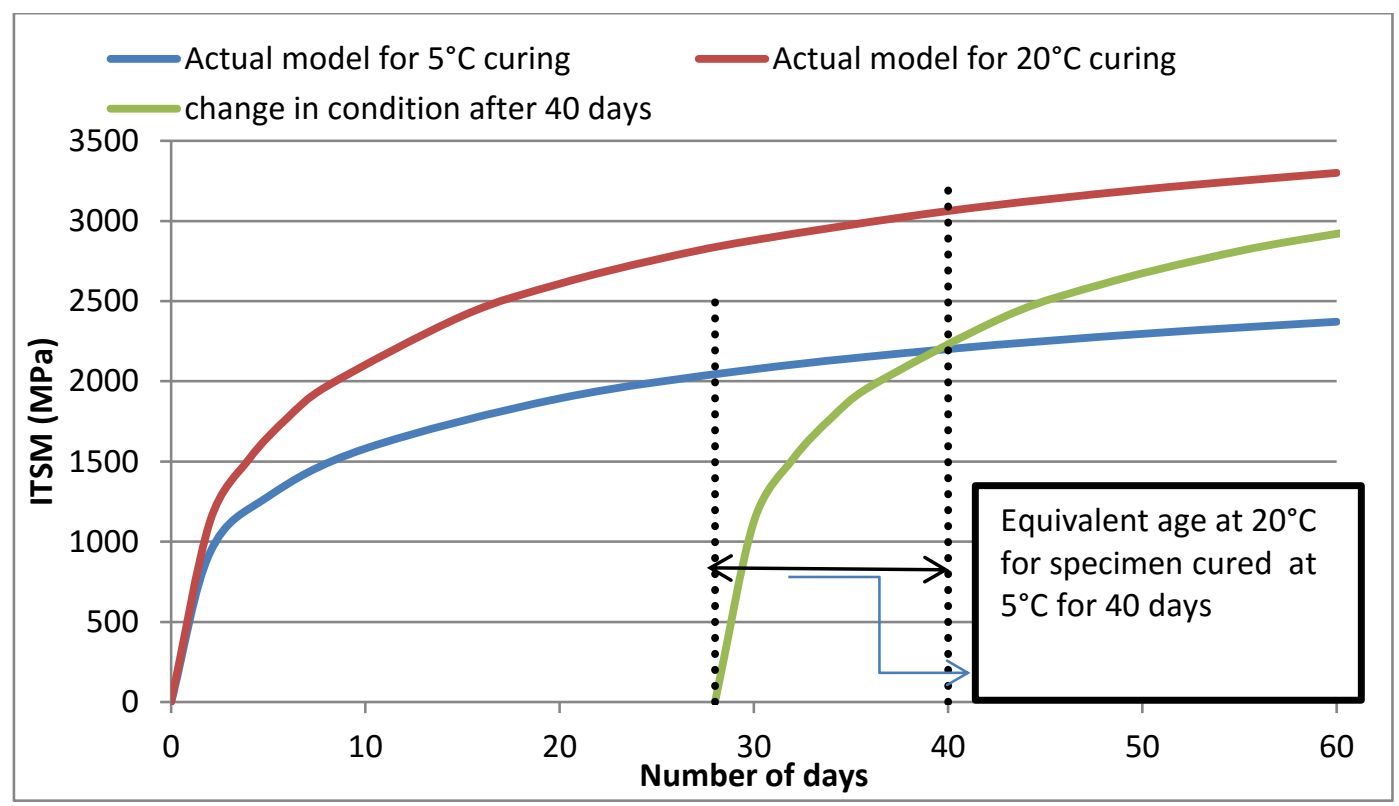




\subsubsection{Formulating the effect of temperature on strength (stiffness) gain}

As rate of strength or stiffness gain is dependent on the curing temperature it is important to formulate temperature dependency in maturity - strength models. This can be done by a temperature dependent factor called the rate constant $(\mathrm{k})$, which is the initial slope of the strength (or stiffness) versus time of the curing curve at a specific constant temperature. Carino et al., (1992) [15] examined the following relationship for describing the rate constant $\mathrm{k}(\mathrm{T})$ as a function of temperature.

$$
\boldsymbol{k}(\boldsymbol{T})=A e^{B T}
$$

Equation 7

$$
\text { Where, } A=\text { the value of the rate constant at } 0{ }^{\circ} \mathrm{C}
$$

\subsubsection{Strength - Maturity Relationships}

Many equations have been proposed to model the strength gain of concrete, but three are often used. These three functions are the exponential, hyperbolic and logarithmic functions, which are defined as follows [13]:

\section{Exponential:}

$$
S=S_{u} e^{-\left[\frac{\tau}{M}\right]^{\beta}}
$$

Equation 8

Where, $\mathrm{S}=$ compressive strength $(\mathrm{MPa}), \mathrm{S}_{\mathrm{u}}=$ limiting compressive strength (MPa), $\mathrm{M}=$ maturity index (hours), $\tau=$ characteristic time constant (hours), and $\beta=$ shape parameter.

\section{Hyperbolic:}

$S=S_{u} \frac{k\left(M-M_{0}\right)}{1+k\left(M-M_{0}\right)}$

Equation 9

$S=S_{u} \frac{\sqrt{k\left(M-M_{0}\right)}}{1+\sqrt{k\left(M-M_{0}\right)}}$

Equation 10

Where, $\mathrm{M}_{\mathrm{o}}=$ maturity when strength development is assumed to begin $\left({ }^{\circ} \mathrm{C} \cdot\right.$ hours or hours $)$, and $\mathrm{k}=$ rate constant $\left(1 /\left[{ }^{\circ} \mathrm{C} \bullet\right.\right.$ hours $]$ or $1 /$ hours $)$.

The differences between Eq. 9 and Eq. 10 as stated by Carino (2001) [10] are in terms of the hydration kinetics of individual cement particles. Eq. 9 is derived based on linear kinetics, which means that the degree of hydration of an individual cement particle is a linear function of the product of time and the rate constant. Eq. 6-10 is based on parabolic kinetics. Thus Eqs. $9 \& 10$ are termed as the linear hyperbolic and parabolic hyperbolic models.

\section{Logarithmic:}

$$
S=\frac{a}{s_{0}}+\frac{b}{s_{0}} \log M
$$

Equation 11

Where, $S_{0}$ is strength when strength development is assumed to begin. The constants $a$ and $b$ are related to the water - cement ratio of the concrete and the type of cement. 


\subsection{Applicability of Maturity method to FBMs}

As discussed, the maturity method is a technique commonly used in the concrete industry to account for the combined effects of time and temperature on the strength gain. The notion of applying the maturity method arises from the fact that the stiffness of a given FBM is dependent on age and temperature history as seen in the previous sections. Moreover, similar to concrete, at early age temperature has a predominant effect on stiffness gain in FBMs. On account of this temperature dependency it is not straightforward to estimate the in-situ properties based on the laboratory test data obtained under standard laboratory conditions [13]. A function of time and temperature was considered an appropriate approach to describe the behaviour of these materials [12]. Moreover, Doyle et al. [9] also identified that in-situ properties of cold bituminous emulsion mixes can be estimated by the maturity approach. Therefore applicability of the maturity method to FBM stiffness gain will be explored and modifications are proposed for predicting stiffness as accurately as possible.

Modifications to the maturity or time-temperature functions were needed as the mechanism by which FBMs gain strength is different from that of concrete. The primary difference is in the definition of curing in the concrete industry and for FBMs. With regard to concrete, curing is a process in which the concrete is protected from loss of water and the concrete strength development occurs during the curing period when water is available for cement hydration. In contrast to that, for FBMs curing is a process in which the compacted material discharges water through evaporation and gains stiffness or tensile strength by formation of continuous bituminous mastic film [16]. The other characteristic of concrete is its 'crossover behaviour', where concrete cured at higher temperature initially has higher strength but later has lower strength than concrete cured at lower temperature. The crossover behaviour of concrete is illustrated in Figure 7. This crossover is because a higher initial temperature results in more than a proportional increase in the initial rate of hydration resulting in reacted products not having time to uniformly distribute within the pores of the hardening paste [10]. However, this crossover effect is not seen in the FBM curing process, as seen in Figure 2. Similar results have also been found in other research investigations $[12,17]$. It has to be noted that the results from these figures were for a curing period of around 30 days whereas crossover relates to the long-term strength of concrete. Nonetheless, analogous results were found for much longer curing periods which will be shown in subsequent sections. 


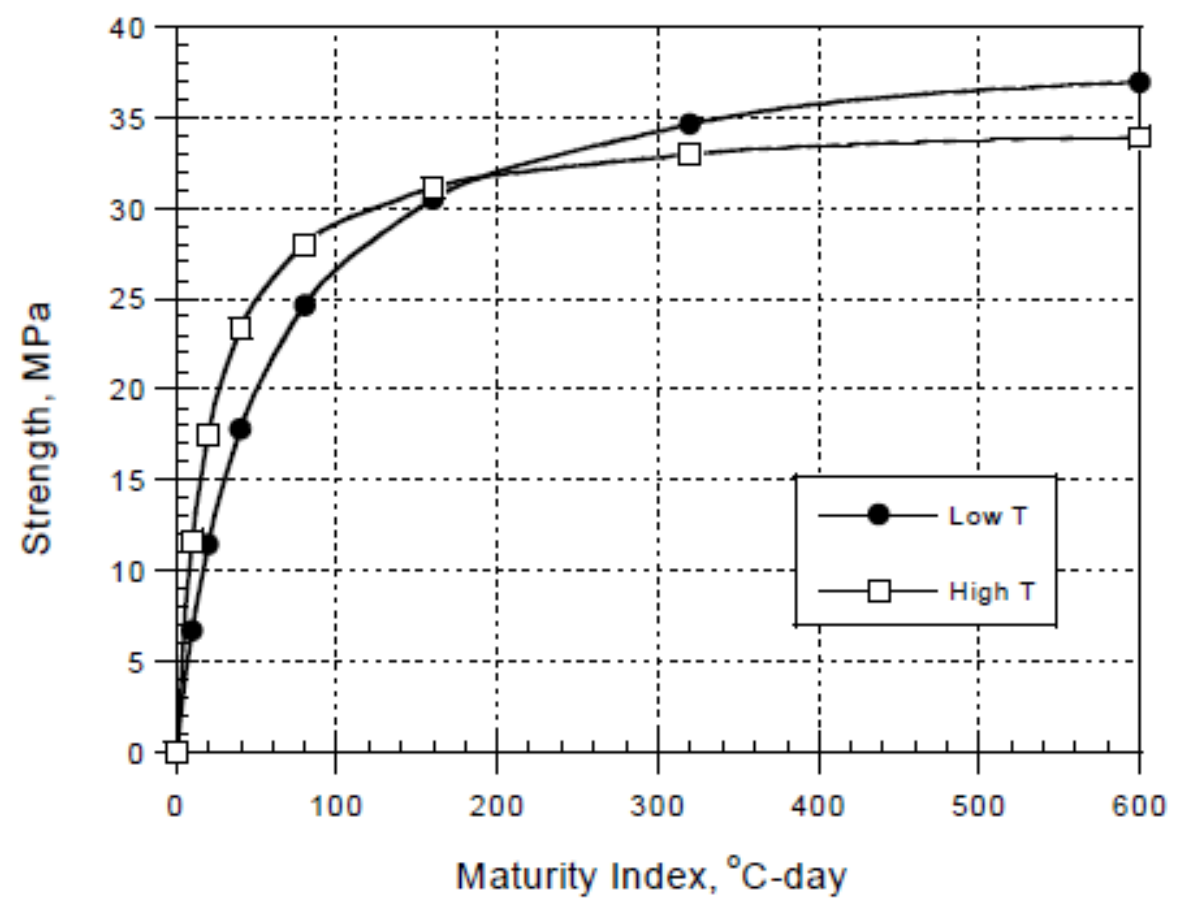

2 Figure 7 The crossover effect in concrete [10]

In the present discussion, maturity refers to the function of temperature and equivalent age computed using a time-temperature function. This is a slightly different interpretation from the definition given by Malhotra and Carino [13] in which maturity was referred to either a temperature - time factor computed using the Nurse-Saul function (Eq. 1) or equivalent age computed using any of the maturity functions (Eq. 2, Eq. 4 and Eq. 5). The general steps followed in developing the maturity - stiffness model for each mixture considered are presented below

- The FBM specimens were cured at different curing temperatures $\left(5^{\circ} \mathrm{C}, 20^{\circ} \mathrm{C}\right.$, and $40^{\circ} \mathrm{C}$ ).

- ITSM (stiffness) tests were performed at different intervals of time. The values of rate constant $(\mathrm{k})$ at each temperature were determined by fitting stiffness data to stiffness - age relationships for isothermal conditions.

- Temperature sensitivity factor (B) was determined by fitting the Arrhenius equation (Eq. 7) to rate constant $(\mathrm{k})$ versus temperature data.

- Age conversion factor $(\alpha)$ was calculated (Eq. 6) for each time period over which the ITSM test was conducted.

- Equivalent age ( $\left.t_{\mathrm{e}}\right)$ was obtained for each time period using Eq. 5.

- Maturity was calculated for all test data and plotted against stiffness.

- A best fit maturity - stiffness relationship was obtained by fitting maturity versus stiffness data.

The methodology adopted for the maturity - strength relationship will be explained with reference to the $50 \% \mathrm{RAP}+1 \%$ cement mixture. 


\subsubsection{Stiffness-age relationships}

It was identified in the previous section that a logarithmic fit best describes the stiffness increase of FBMs over time (Figure 2). This is because the logarithmic function provided a good prediction of the high initial rate of stiffness gain which is a characteristic of FBMs. However, the logarithmic function overestimated the stiffness of these mixtures over a long period of time. This can be seen in Figure 8 to Figure 10. These figures present the average ITSM test results for the FBM (50\%RAP + 1\% Cement) cured and monitored over a long period (296 days). The short term curing data (up to 30 days) is equivalent to that presented in Figure 2. The specimens cured at $30^{\circ} \mathrm{C}$ were not cured long term and were used for validation of the approach. Because of the overestimation of the logarithmic function in the long term, a hyperbolic equation is used to fit the stiffness data over time. Hyperbolic equations for strength gain under isothermal curing for concrete are as shown in Eq. 12 and Eq. 13. Theoretical analysis of the expressions (hyperbolic equations) to describe the strength development of concrete can be found in Carino (1984)[18]. In the analysis it was also shown that under isothermal conditions the strength gain of the concrete can be described by a hyperbolic curve (Eq. 12 and Eq. 13). The maturity term (M) was replaced with time term (t) from Eq. 8 and Eq. 9.

$$
\begin{aligned}
& S=S_{u} \frac{k\left(t-t_{0}\right)}{1+k\left(t-t_{0}\right)} \\
& S=S_{u} \frac{\sqrt{k\left(t-t_{0}\right)}}{1+\sqrt{k\left(t-t_{0}\right)}}
\end{aligned}
$$

Equation 12

Equation 13

Where, $S$ is strength at age $t ; S_{u}$ is the asymptotic value of the strength for the hyperbolic function that fits the data; $\mathrm{k}$ is the rate constant which is related to the rate of strength gain at a constant temperature; $t_{0}$ is age at the start of strength development. It was also shown by Carino (1984) that these parameters are temperature dependent and can be obtained by conducting a regression analysis on strength data obtained at different curing temperatures.

In the present study as the material property considered is stiffness (ITSM), strength (S) is replaced by stiffness (E) in Eq. 12 and Eq. 13. It is assumed that the stiffness development starts at age $t_{0}$ as per these models. However, in the present study it was assumed that stiffness development starts immediately after compaction $\left(\mathrm{t}_{0}=\right.$ 0). Thus the two equations (Eq. 12 and Eq. 13) can be re-written as follows.

$$
\begin{aligned}
& E=E_{u} \frac{k t}{1+k t} \\
& E=E_{u} \frac{\sqrt{k t}}{1+\sqrt{k t}}
\end{aligned}
$$

The stiffness - time data for the three curing temperatures $\left(5^{\circ} \mathrm{C}, 20^{\circ} \mathrm{C}\right.$ and $\left.40^{\circ} \mathrm{C}\right)$ was fitted by the hyperbolic relationships given by Eq. 14 and Eq. 15 . There are several approaches to determine the parameters limiting stiffness $\left(\mathrm{E}_{\mathrm{u}}\right)$ and $\mathrm{k}$. The simplest approach is to conduct regression analysis using the least squares curve fitting technique. The data in Figure 8 to Figure 10 were subjected to regression analysis and the best fit curves for logarithmic and the two hyperbolic curves can be seen in the figures. As can be seen, the parabolic hyperbolic equation (Eq. 15) best described the trend. The coefficient of determination, $\mathrm{R}^{2}$, found from regression analysis for the test data confirmed that the parabolic hyperbolic equation is the best fit to the stiffness over time. The minimum $\mathrm{R}^{2}$ was found to be $0.78,0.9,0.96$ respectively for logarithmic, linear hyperbolic and parabolic hyperbolic models.

The limiting stiffness, $\mathrm{E}_{\mathrm{u}}$ and the rate constant, $\mathrm{k}$ obtained from the regression analysis for each curing temperature are summarised in Table 2. 
Long term curing data fitted to the hyperbolic parabolic model for $50 \% \mathrm{RAP}+1 \%$ 2 Cement-FBM for all curing temperatures is presented in Figure 11. It is evident from 3 the figure that the limiting stiffness $\left(\mathrm{E}_{\mathrm{u}}\right)$ is directly dependent on curing temperature. 4 The higher the curing temperature, the higher was the limiting stiffness which means 5 that there was no crossover effect found in FBMs. Moreover, the temperature 6 dependency of the limiting stiffness was nearly linear.

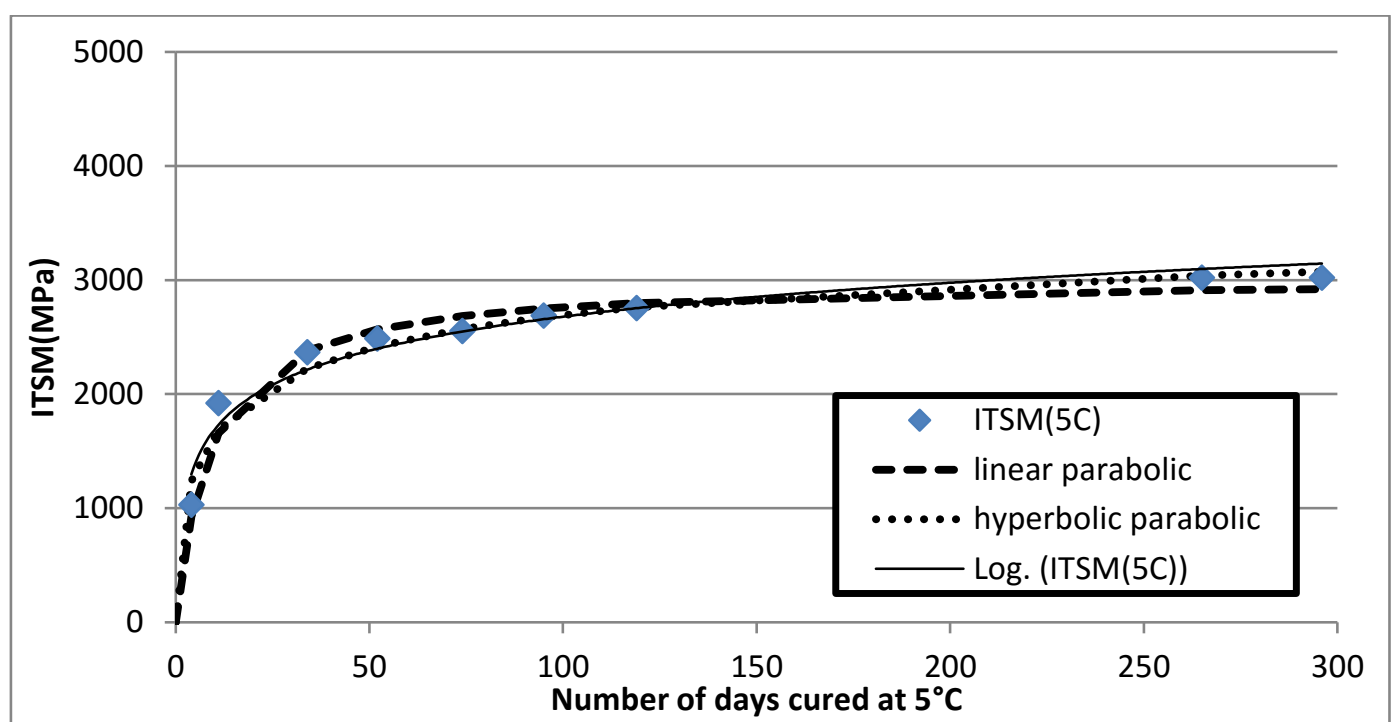

9 Figure 8 Stiffness development relationships for 50\% RAP + 1\% Cement- FBM 10 cured at $5^{\circ} \mathbf{C}$

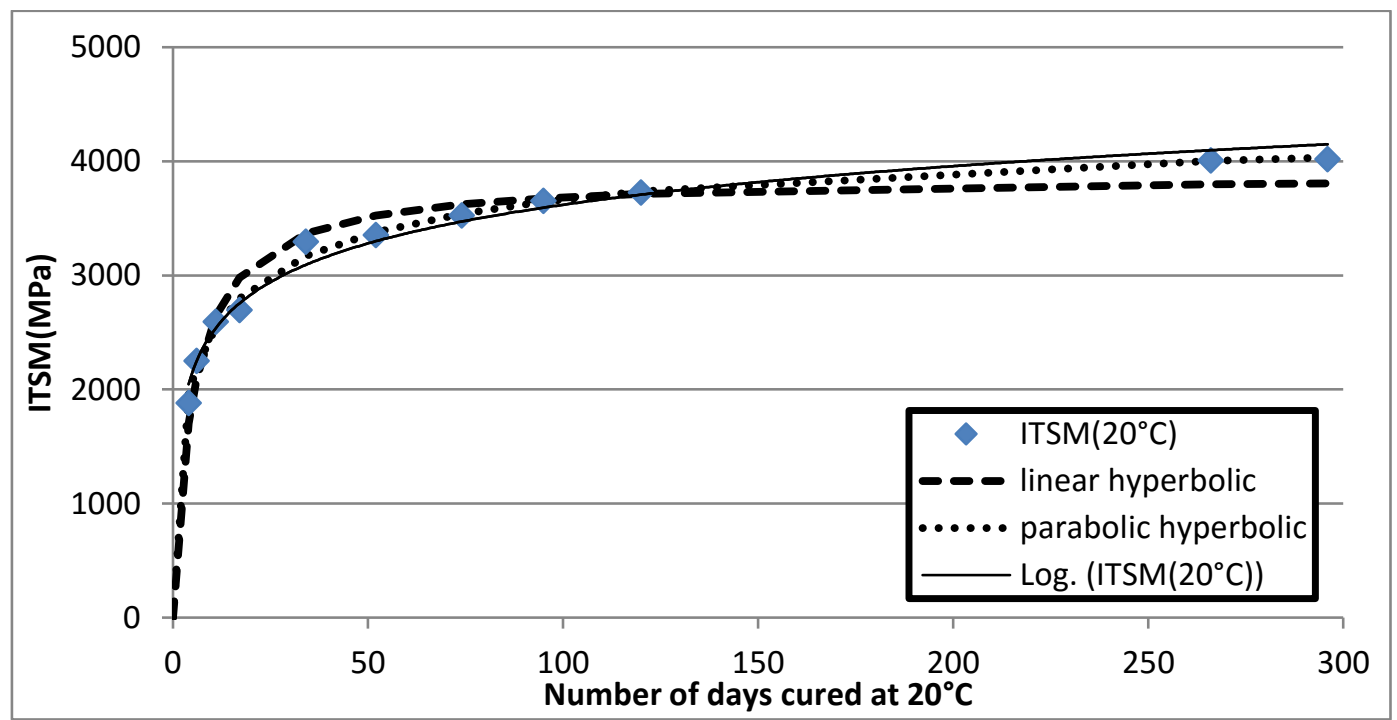

12 Figure 9 Stiffness development relationships for $\mathbf{5 0 \%}$ RAP + 1\% Cement- FBM 13 cured at $20^{\circ} \mathrm{C}$ 


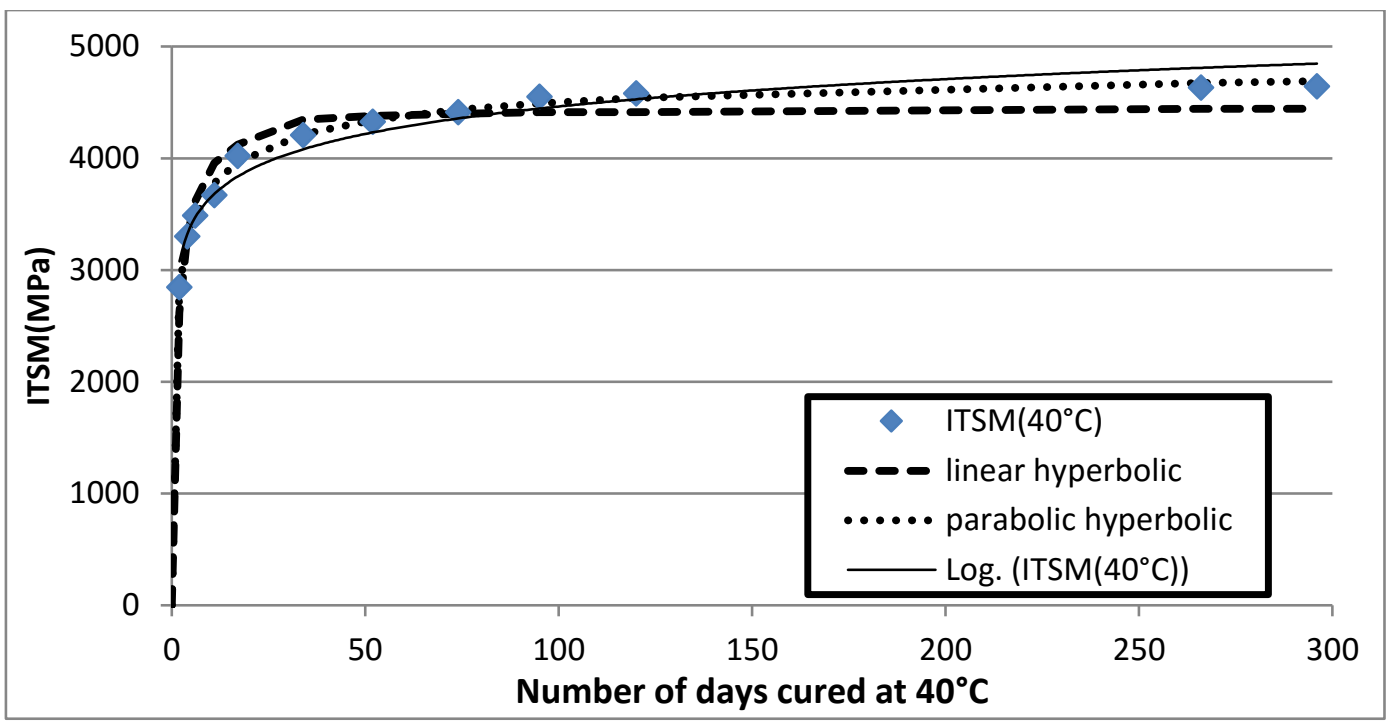

2 Figure 10 Stiffness development relationships for 50\% RAP + 1\% Cement- FBM

3 cured at $40^{\circ} \mathrm{C}$

5 Table 2 Summary of parameters obtained by fitting age versus stiffness data

\begin{tabular}{|c|c|c|c|c|c|c|}
\hline Temperature & \multicolumn{2}{|c|}{$\mathbf{5}^{\circ} \mathbf{C}$} & \multicolumn{2}{c|}{$\mathbf{2 0}^{\circ} \mathbf{C}$} & \multicolumn{2}{c|}{$\mathbf{4 0}^{\circ} \mathbf{C}$} \\
\hline Parameters & $\mathbf{k}(\mathbf{1} /$ day $)$ & $\mathbf{E u}_{\mathbf{u}}(\mathbf{M P a})$ & $\mathbf{k}(\mathbf{1 / d a y})$ & $\mathbf{E u}(\mathbf{M P a})$ & $\mathbf{k}(\mathbf{1} /$ day $)$ & $\mathbf{E u}_{\mathbf{u}}(\mathbf{M P a})$ \\
\hline $\mathbf{5 0 \% R A P + 1 \% C e m e n t ~}$ & 0.06 & 3622 & 0.13 & 4687 & 0.9 & 4977 \\
\hline $\mathbf{5 0 \% R A P}$ & 0.01 & 2842 & 0.08 & 3377 & 0.72 & 3489 \\
\hline $\mathbf{1 0 0 \%}$ VA+1\%Cement & 0.07 & 3199 & 0.28 & 4253 & 2.16 & 4556 \\
\hline $\mathbf{1 0 0 \% V A}$ & 0.02 & 2620 & 0.05 & 3834 & 0.58 & 3895 \\
\hline
\end{tabular}

6

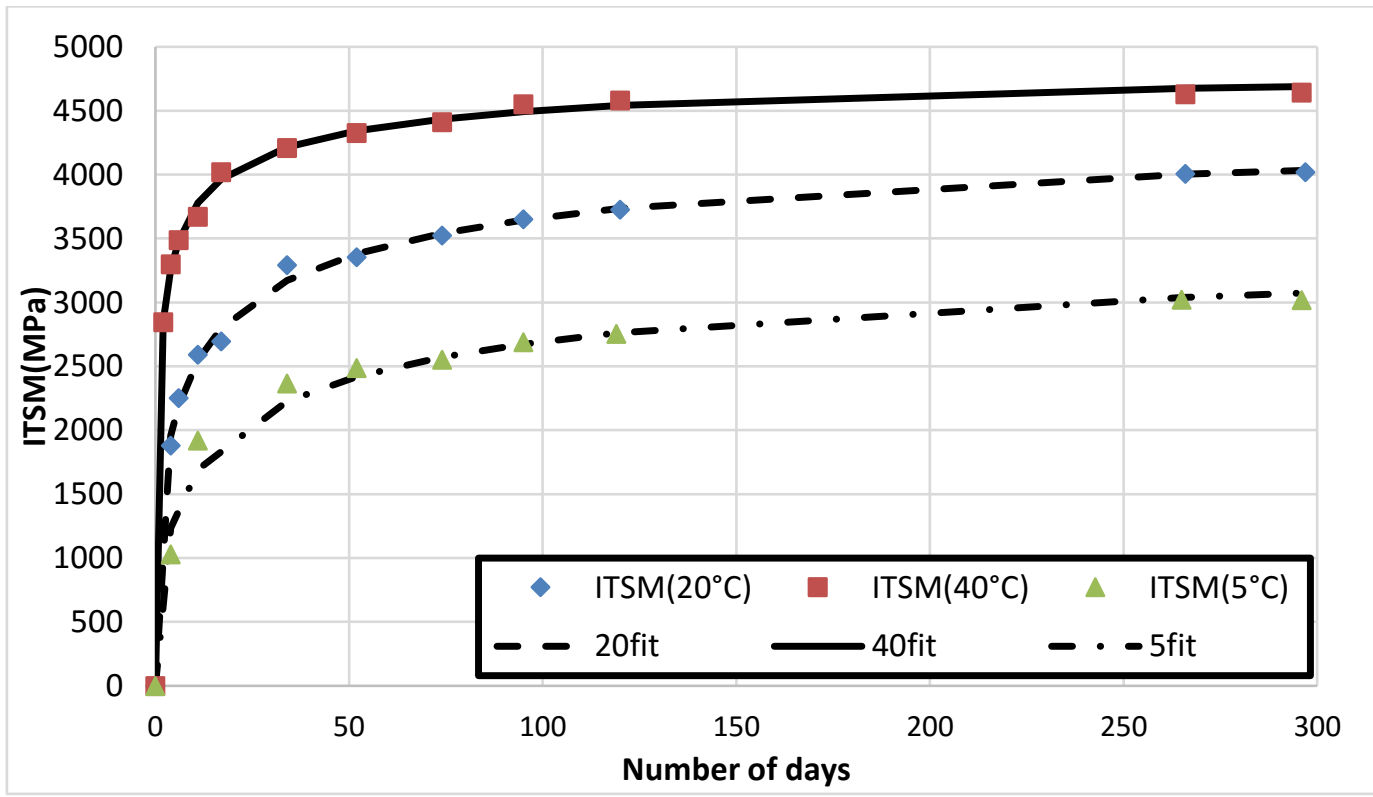

8 Figure 11 Long term curing data fitted to hyperbolic parabolic model for

$9 \quad 50 \%$ RAP+1\% Cement - FBM 


\subsubsection{Temperature sensitivity factor}

This section examines the variation of the value of the rate constant $(\mathrm{k})$ with curing temperature in order to obtain the temperature sensitivity factor (B). As was discussed, the rate constant $(\mathrm{k})$ is related to the rate of stiffness gain at a constant temperature, and it was obtained from an appropriate equation of stiffness gain versus age. In order to describe stiffness development under variable curing temperatures it is necessary to determine how the rate constant is affected by curing temperature. For this the $\mathrm{k}$ values in Table 2 are plotted against curing temperature as can be seen in Figure 12. The best fit Arrhenius equation (Eq. 7) was determined. The parameters 10 that were obtained in the analysis are tabulated in Table 3. A is the value of the rate 11 constant at $0^{\circ} \mathrm{C}$ and $\mathrm{B}$ is the temperature sensitivity factor.

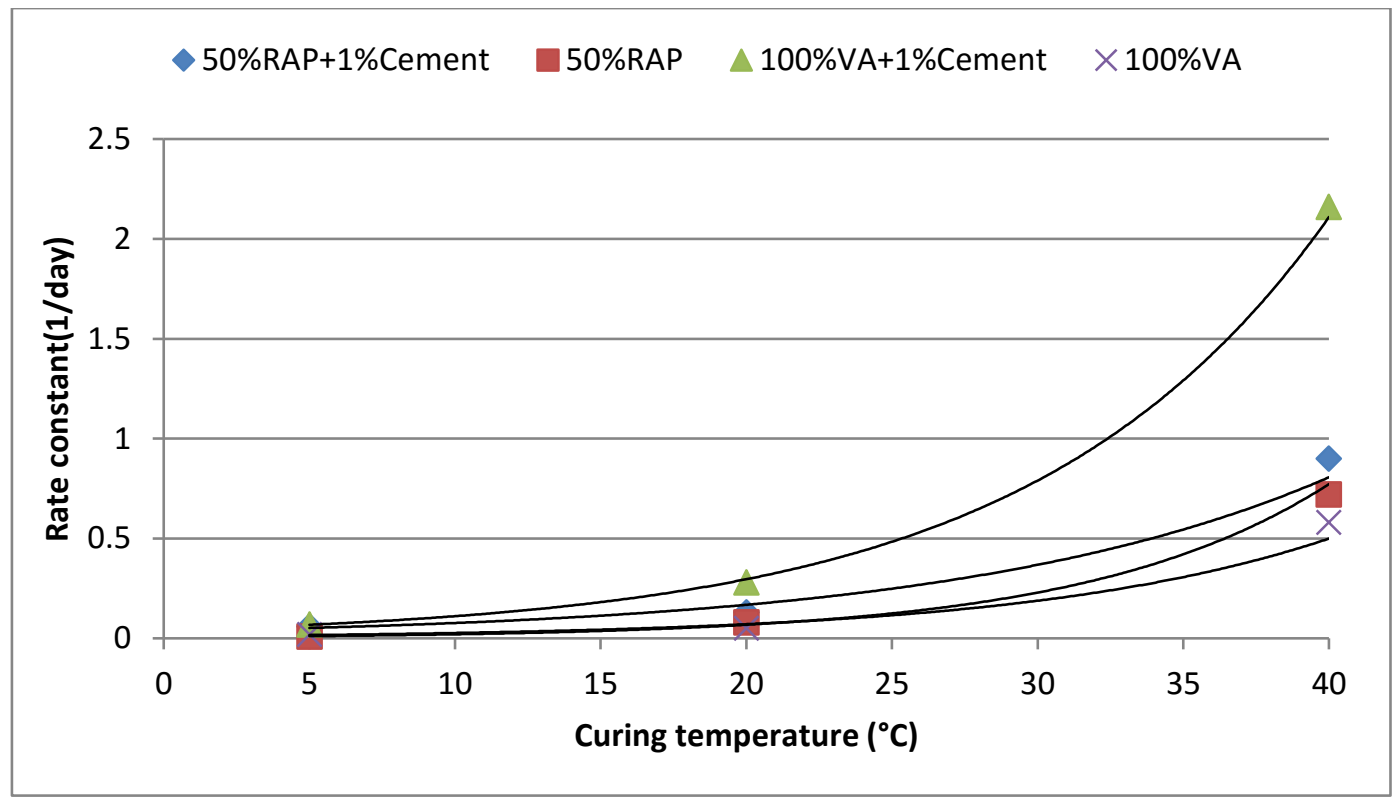

14 Figure 12 Variation of rate constant (k) with temperature

15 Table 3 Summary of parameters obtained by fitting age versus stiffness data

\begin{tabular}{|c|c|c|c|}
\hline Mixture type & $\mathbf{A}$ & $\mathbf{B}\left(\mathbf{1} /{ }^{\circ} \mathbf{C}\right)$ & R-squared \\
\hline 50\%RAP+1\% Cement & 0.035 & 0.078 & 0.97 \\
\hline 50\%RAP & 0.006 & 0.121 & 0.99 \\
\hline 0\% RAP+1\% Cement & 0.041 & 0.098 & 0.99 \\
\hline 0\% RAP & 0.01 & 0.097 & 0.96 \\
\hline
\end{tabular}

\subsubsection{Age conversion factor and equivalent age}

The age conversion factors for different temperatures were calculated using Eq. 6. The equation utilised the temperature sensitivity factors from Table 3 . The reference temperature to which age was converted was assumed as $20^{\circ} \mathrm{C}$. The age conversion factor $(\alpha)$ obtained for different mixtures is presented in Figure 13. The age conversion factor $(\alpha)$ at $20^{\circ} \mathrm{C}$ is 1 as the reference temperature considered in the study is $20^{\circ} \mathrm{C}$. The equivalent age is the duration of time that a specimen would need to be cured at a specified reference temperature (in the present case $20^{\circ} \mathrm{C}$ ) to equal the maturity of the specimen cured at various temperatures. The equation for equivalent age used in the present study is as given in Eq. 5. For developing the maturity - stiffness 
relationships, the specimens are cured at isothermal conditions. Therefore, for isothermal condition in Eq. 5, $\Delta \mathrm{t}$ can be replaced with $\mathrm{t}(\Sigma \Delta \mathrm{t})$ and summation is not needed. Thus Eq. 5 can be re-written as Eq. 16 in which $t$ is the elapsed time of test since compaction, $\mathrm{B}$ is temperature sensitivity factor (Table 3 ), $\mathrm{T}$ is curing temperature and $\mathrm{T}_{\mathrm{r}}$ is the reference temperature (in the present case $\mathrm{T}_{\mathrm{r}}$ was considered as $20^{\circ} \mathrm{C}$ ).

$$
t_{e}=e^{B\left(T-T_{r}\right)} * t
$$

Equation 16

It has to be noted that for calculating in-situ maturity where variable temperature exists $\mathrm{Eq} .5$ has to be used as it is. The equivalent age obtained using Eq. 16 for a reference temperature of $20^{\circ} \mathrm{C}$ is plotted against stiffness in Figure 14 for the 50\%RAP

$10+1 \%$ cement FBM mixture. The equivalent age - stiffness data for $20^{\circ} \mathrm{C}$ condition 11 remains the same as in Figure 9 as the reference temperature considered was $20^{\circ} \mathrm{C}$.

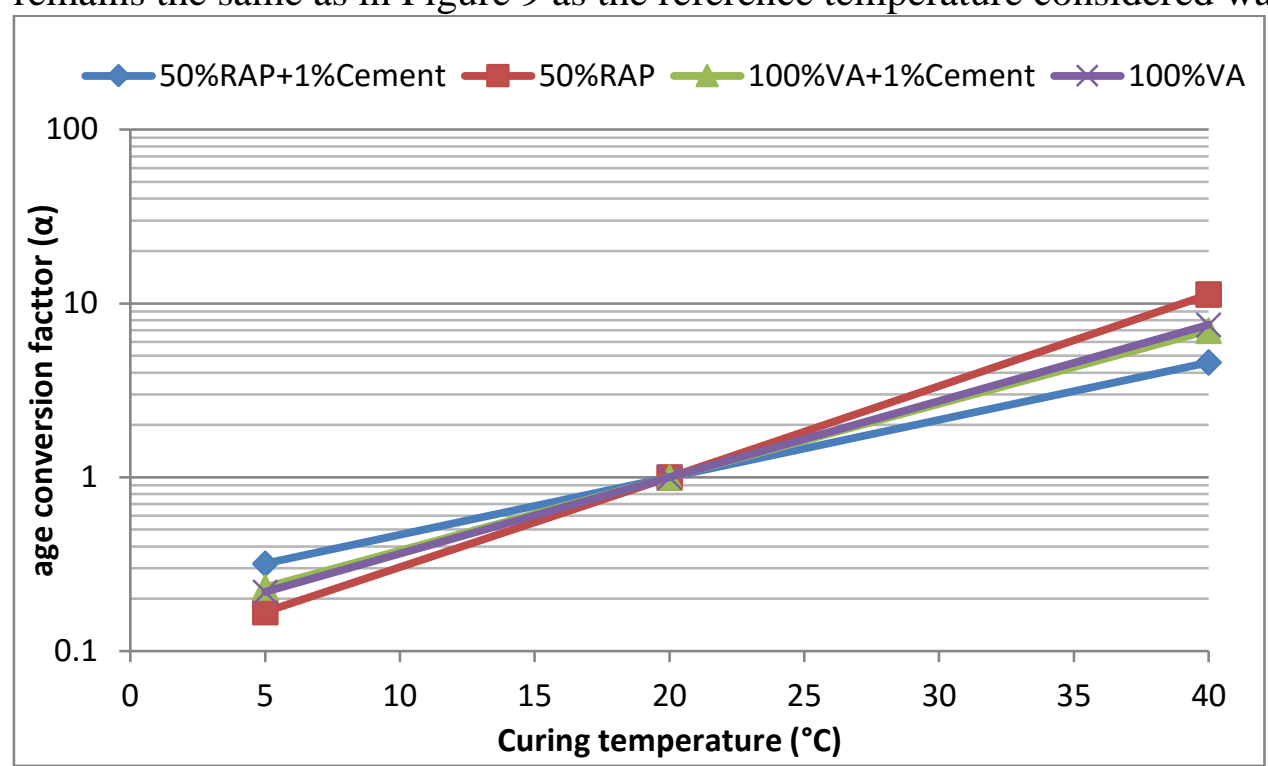

13 Figure 13 Age conversion factor for reference temperature of $20^{\circ} \mathrm{C}$

14

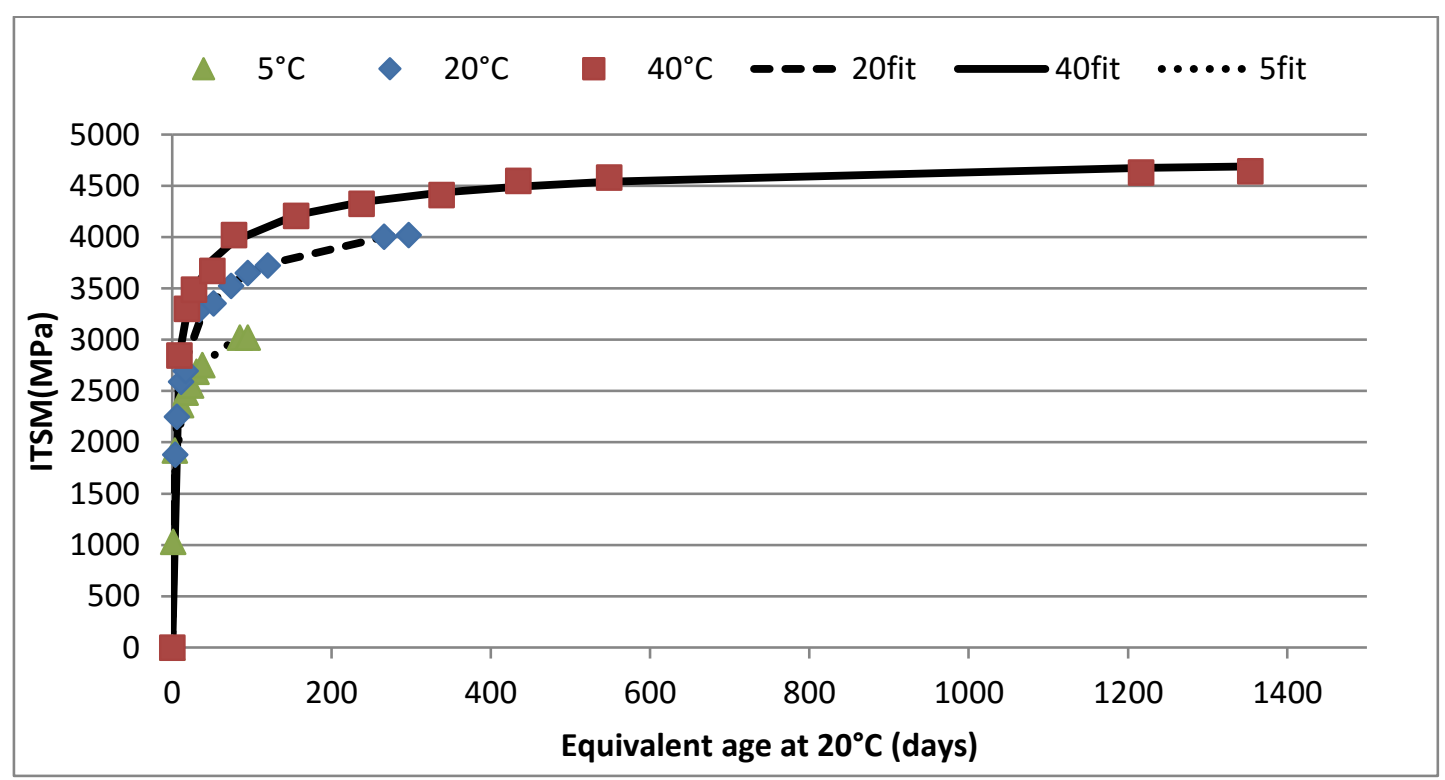

16 Figure 14 Equivalent age at $20^{\circ} \mathrm{C}$ for $50 \% \mathrm{RAP}+1 \%$ Cement - FBM

\section{$17 \quad$ 4.2.4 Maturity - stiffness relationship}

According to the standard definition of maturity, samples of the same FBM

19 should have equal stiffness if they have equal maturities irrespective of their curing 
1 histories. As the present study is dealing with the equivalent age approach the term 2 maturity refers to equivalent age. Figure 14 clearly shows that the equivalent age 3 doesn't have a unique relationship with stiffness. The traditional maturity rule is 4 therefore an approximation in the present case as it assumes that the limiting stiffness 5 or strength of the mixture subjected to continuous curing is not affected by early age 6 temperature history. However, as was shown in Figure 7 and Figure 11, this was not 7 the case in either FBMs or concrete. In both cases it is clear that the curing temperature 8 not only affects the initial rate of stiffness but also the limiting values. Therefore the 9 traditional maturity rule results in inaccurate results.

10 To resolve the nature of the above problem, Carino (1984) introduced a model 11 for concrete called a rate constant model which states that there exists a unique 12 relationship between relative strength $(\mathrm{S} / \mathrm{Su})$ and equivalent age. The relative strength 13 can be obtained by dividing strength by the limiting strength obtained for the curing 14 temperature that the specimen experienced. Figure 15 is a plot of the relative stiffness versus equivalent age obtained for the 50\%RAP $+1 \%$ Cement mixture. The data points very much group around a single curve and therefore it can be interpreted that there exists a relationship between relative strength and equivalent age. However, in FBMs unlike concrete there is no crossover effect as was shown in Figure 11. Moreover, the limiting stiffness (Table 2) was found to have a nearly linear relationship with temperature. Therefore a temperature term is introduced into the equivalent age function (Eq. 16). The resulting function is Eq. 17. This equation is valid for isothermal curing. However, for variable temperature conditions, the equation becomes as shown in Eq. 18. This equation is analogous to the Nurse-Saul maturity function (Eq. 1) in which the time term $(\Delta t)$ is replaced with equivalent time $\left(\Delta\right.$ te) and the datum temperature is $0^{\circ} \mathrm{C}$.

$M=t_{e} * T=e^{B\left(T-T_{r}\right)} * t * T$

Equation 17

$M=\sum_{0}^{t} \Delta t_{e} * T$

Equation 18

Maturity using Eq. 17 was calculated and plotted against stiffness in Figure 16. The datum temperature $\left(\mathrm{T}_{0}\right)$ was assumed as $0^{\circ} \mathrm{C}$ as there is direct influence of water evaporation on the mixture stiffness gain. The figure clearly shows that the data points are grouped around a single curve whose equation is as in Eq. 19 which is the same equation as Eq. 10 except that the datum temperature was assumed as $0^{\circ} \mathrm{C}$. The stiffness values were fitted to maturity values with Eq. 19 using the least squares curve fitting technique and the parameters $\mathrm{E}, \mathrm{E}_{\mathrm{u}}$ and $\mathrm{k}$ were obtained. The parameters obtained for all the mixtures considered in the present study are tabulated in Table 4.

37

$E=E u \frac{\sqrt{k M}}{1+\sqrt{k M}}$

Equation 19 


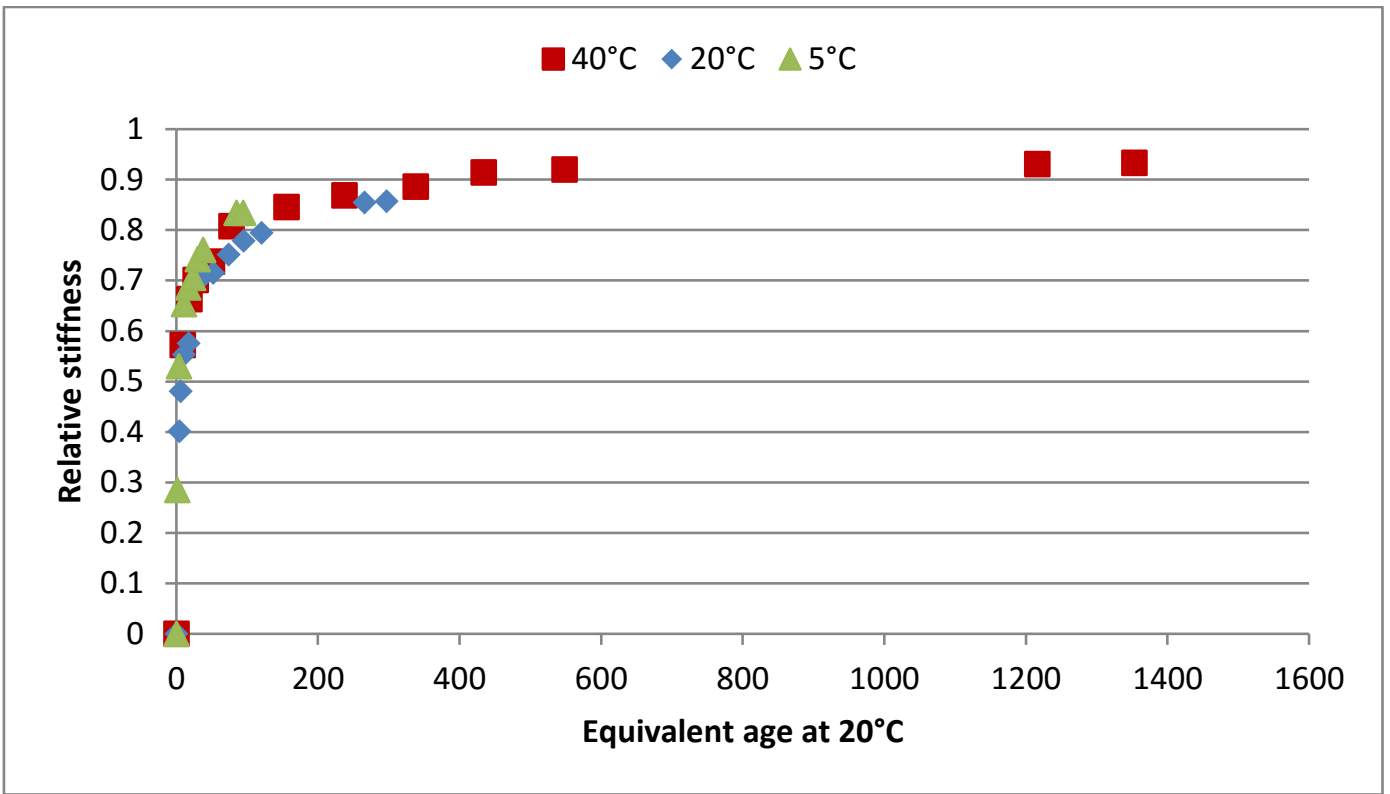

Figure 15 Relative stiffness versus equivalent age at $20^{\circ} \mathrm{C}$ for $50 \% \mathrm{RAP}+1 \%$ Cement FBM

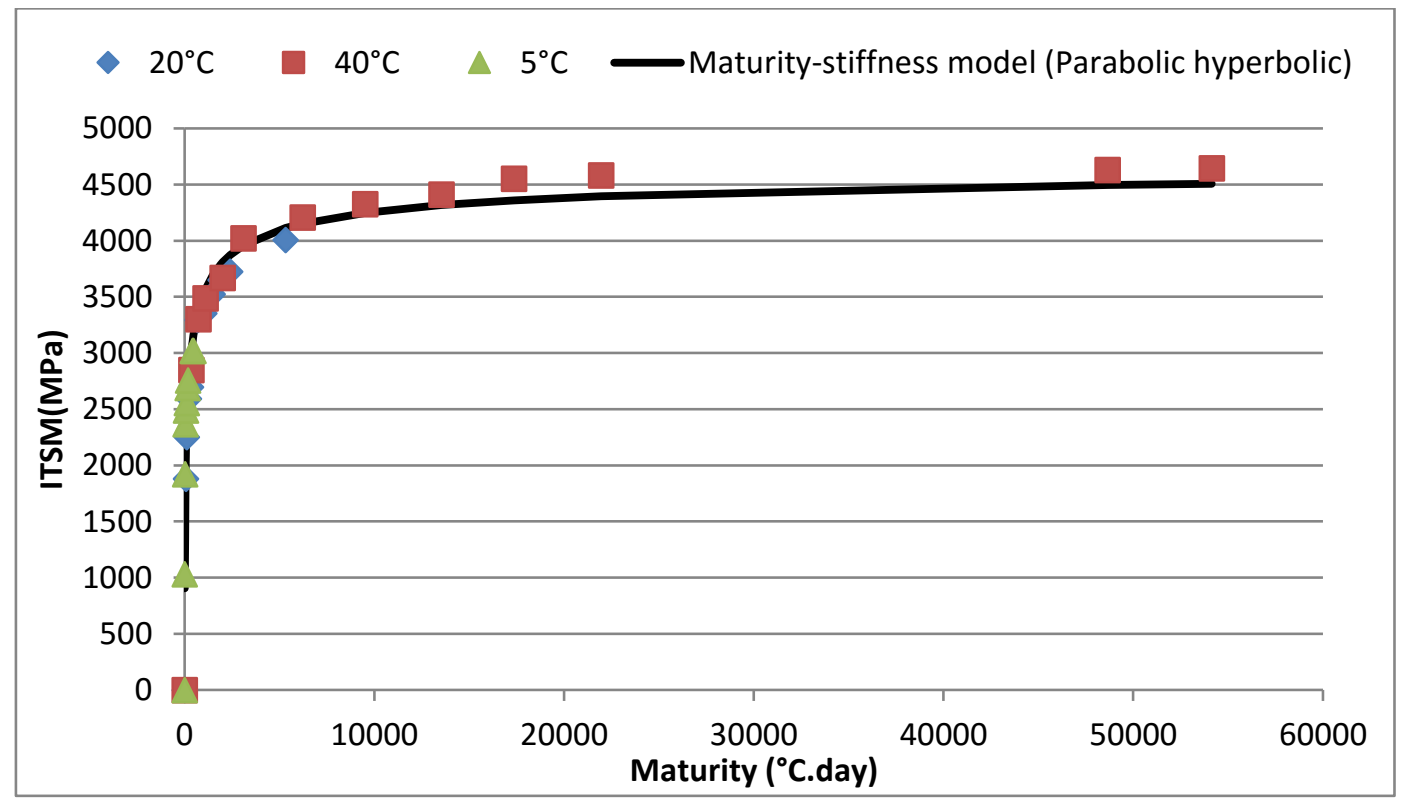

7 Figure 16 Maturity and stiffness relationship for 50\% RAP + 1\% Cement- FBM

8 Table 4 Parameters obtained for Maturity - Stiffness model

\begin{tabular}{|c|c|c|}
\hline FBM - Type & Eu $_{\mathbf{u}}$ (MPa) & k(1/day) \\
\hline 50\%RAP+1\% Cement & 4712 & 0.008 \\
\hline 50\%RAP & 3187 & 0.011 \\
\hline 0\% RAP+1\%Cement & 4384 & 0.013 \\
\hline 0\%RAP & 3764 & 0.002 \\
\hline
\end{tabular}




\subsection{Validation of the method}

The experimental study also included validating the applicability of the maturity - stiffness models to other temperatures (isothermal) that were not included while developing the models. The study also tried to verify how well the model can account for the effect of variations in temperature on FBM curing. For this, three conditions namely short term (less than 10 days), intermediate (between 10 days and 35 days) and long term (between 35 days and 300 days) were considered.

\subsubsection{Isothermal curing temperature}

For verifying isothermal condition, the ITSM test data that was obtained for the curing mechanism study at $30^{\circ} \mathrm{C}$ was used. The stiffness (ITSM) data measured on the specimens cured at $30^{\circ} \mathrm{C}$ obtained for short term and intermediate term was plotted against the stiffness values obtained from the maturity-stiffness model that had been developed (Figure 17 to Figure 20). From these figures, values corresponding to ' $30^{\circ} \mathrm{C}-30^{\circ} \mathrm{C}$ ' are results for isothermal curing which indicate specimens were conditioned at $30^{\circ} \mathrm{C}$ during the early stage (less than 7 days after compaction) and as well as during the intermediate stage (between 10 days and 35 days). These figures indicate that the maturity-stiffness model estimates the stiffness reasonably well in all cases except for 50\% RAP-FBM in which the model has overestimated slightly.

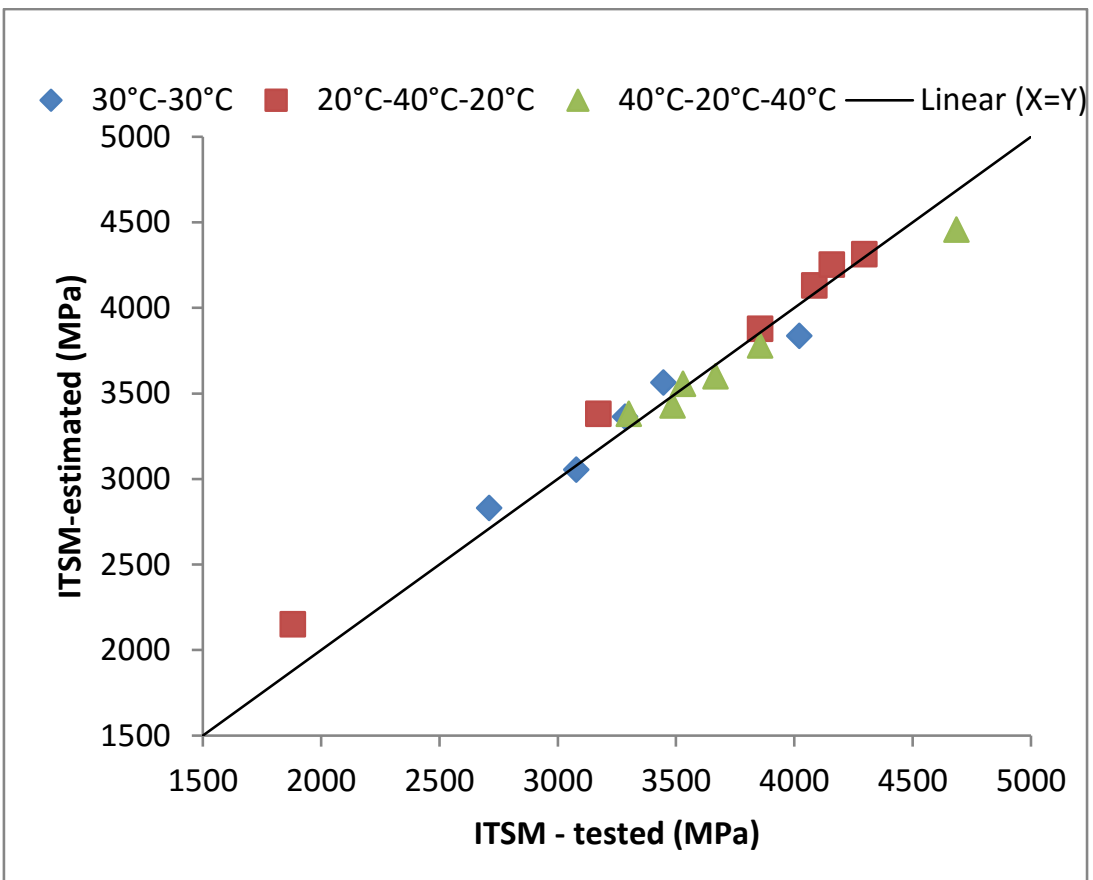

23 Figure 17 Verification of Maturity - Stiffness model for 50\%RAP + 1\% Cement - FBM 


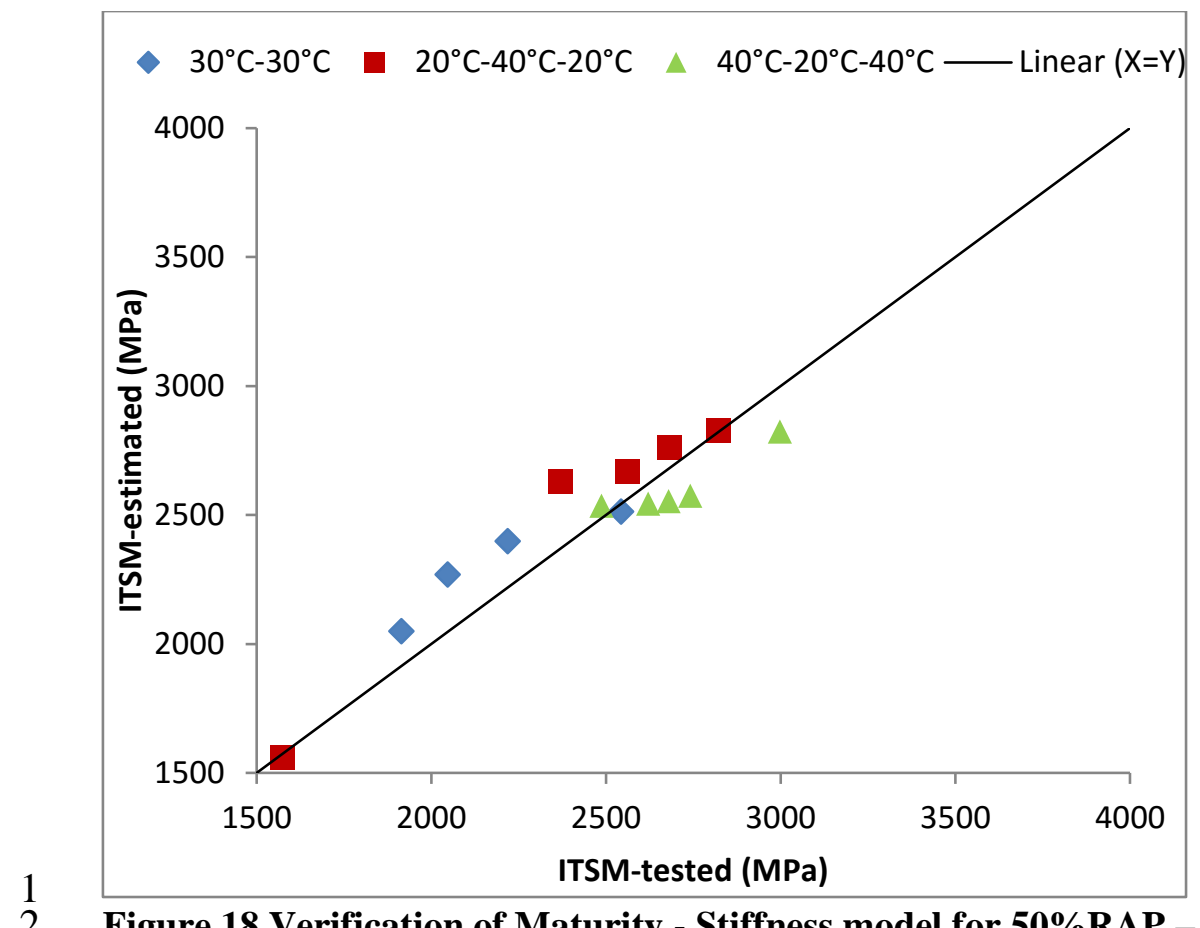

2 Figure 18 Verification of Maturity - Stiffness model for 50\%RAP - FBM

3

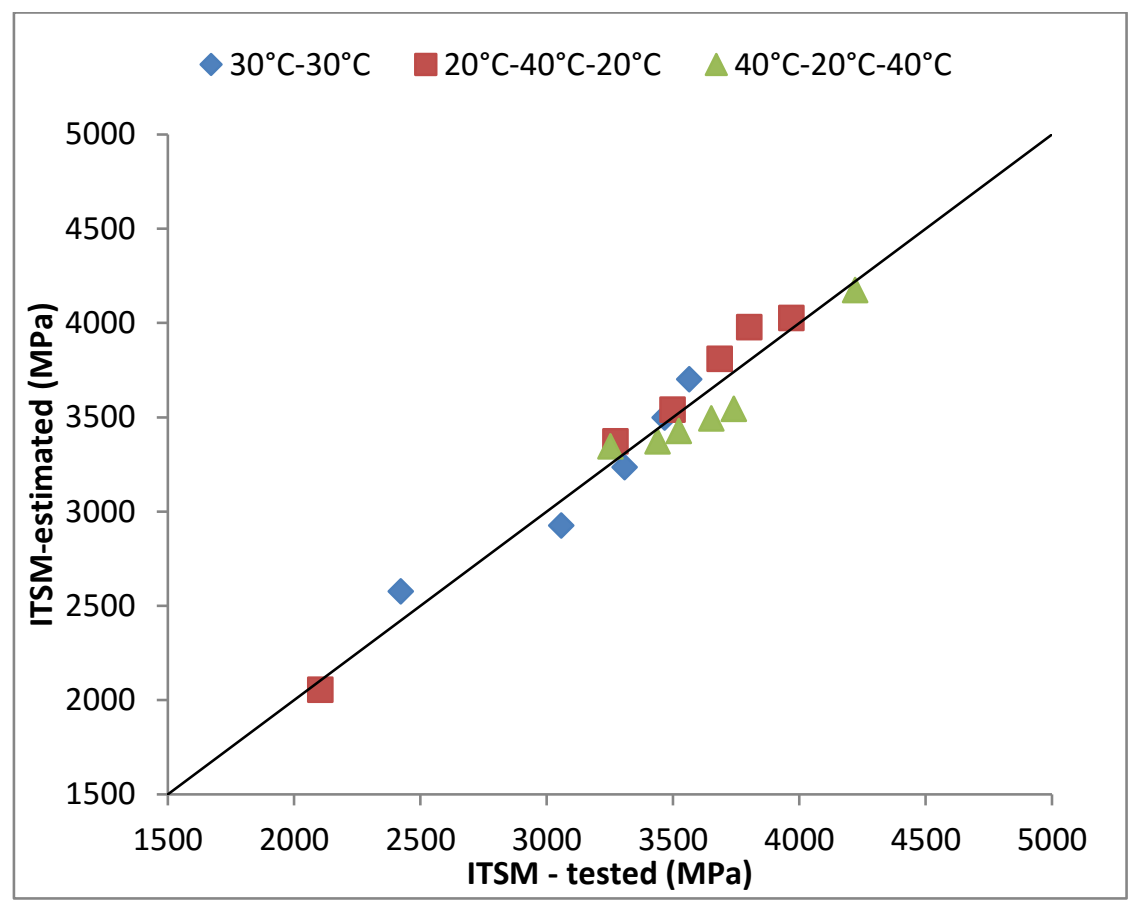

4
5

Figure 19 Verification of Maturity - Stiffness model for 100\% VA+1\% Cement - FBM 


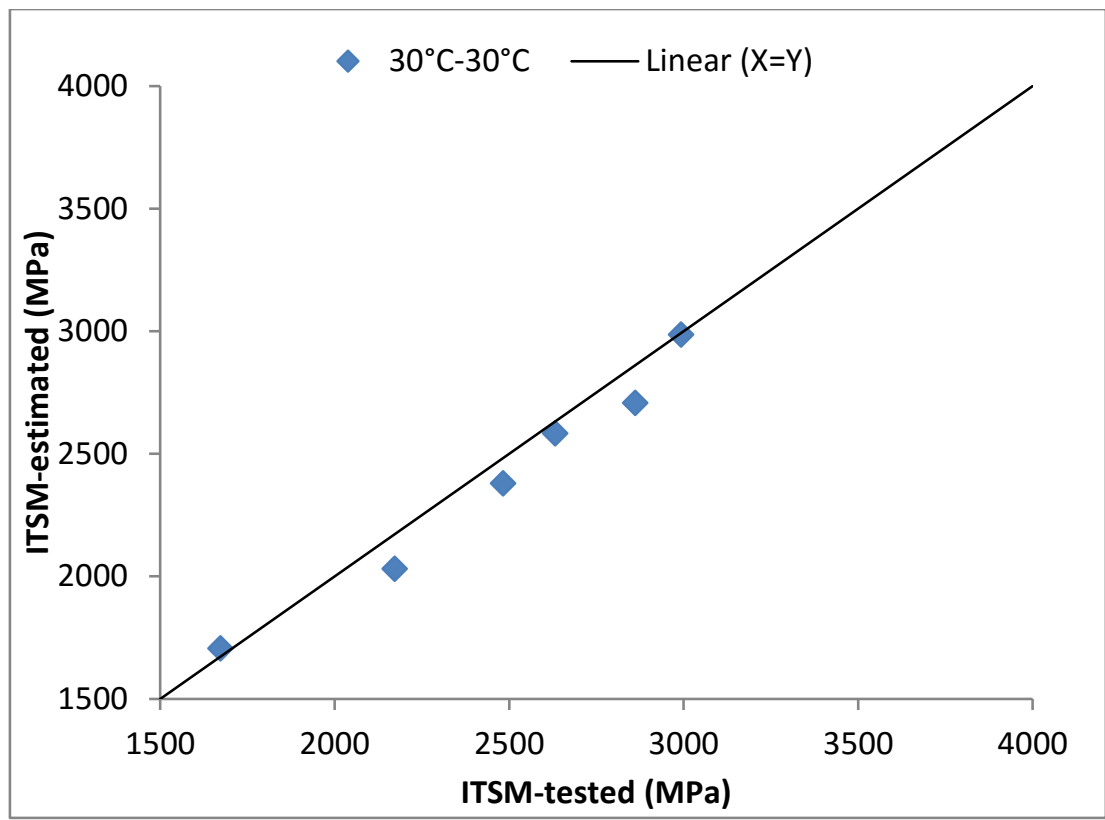

2 Figure 20 Verification of Maturity - Stiffness model for 100\% VA - FBM

\subsubsection{Variable curing temperatures}

To verify how well the maturity-stiffness model addresses varying temperatures, specimens were cured with two variable temperature conditioning sequences. The first case is conditioning the specimens at $20^{\circ} \mathrm{C}$ during the early stage curing (up to 7 days after compaction) and then changing to a $40^{\circ} \mathrm{C}$ cabinet to cure during the intermediate stage ( 7 days to 35 days) and finally the specimen was transferred back to the $20^{\circ} \mathrm{C}$ conditioning cabinet for long term curing. This conditioning sequence is termed as ' $20^{\circ} \mathrm{C}-40^{\circ} \mathrm{C}-20^{\circ} \mathrm{C}$ '. Similarly the second sequence studied was $40^{\circ} \mathrm{C}-20^{\circ} \mathrm{C}-40^{\circ} \mathrm{C}$. The specimens were tested for ITSM at different intervals of time.

Table 5 presents the curing sequence for $20^{\circ} \mathrm{C}-40^{\circ} \mathrm{C}-20^{\circ} \mathrm{C}$ for $50 \%$ RAP+1\%Cement-FBM. It also shows the calculations for maturity and from it the stiffness values that were predicted. Maturity was calculated using Eq. 16 and Eq. 18. Stiffness (ITSM) was estimated using Eq. 19 using corresponding values from Table 4 and maturity values. The first three values calculated in Table 5 are presented in Figure 21 for comparison. The figure illustrates graphically the estimation of stiffness comprising the tested value and estimated value for stiffness from the maturitystiffness model. As can be seen in the figure, the conditioning changed from $20^{\circ} \mathrm{C}$ initially to $40^{\circ} \mathrm{C}$ at 4 days. The dotted lines in the figure demonstrate the actual path of the stiffness increase for this particular sequence of curing. The figure suggests that though the stiffness values obtained from the maturity-stiffness model were marginally higher than the tested values, the model predicted the stiffness adequately in the particular case of 50\% RAP $+1 \%$ Cement FBM as can be seen in Figure 17. Figure 18 and Figure 19 show how well the model predicted stiffness gain for variable temperature conditions for 50\% RAP and 100\% VA + 1\% Cement FBMs.

It is worth noting that the model slightly underestimated the stiffness of the samples which were cured initially at $40^{\circ} \mathrm{C}$ and marginally overestimated specimens that were cured at $20^{\circ} \mathrm{C}$. Underestimation for the $40^{\circ} \mathrm{C}-20^{\circ} \mathrm{C}-40^{\circ} \mathrm{C}$ sequence could be attributed to the slightly conservative nature of the model (Figure 16). The reason for overestimation could probably be the failure of the mixture to gain stiffness at the rate the model estimated after changing the conditioning temperature. This shortcoming 
can also be seen in Figure 21. From the above discussion it can be stated that though 2 estimated stiffness from the developed model marginally differs from the test results, 3 they are close enough to state that the maturity approach provides a satisfactory basis 4 for estimating the stiffness of FBMs. Furthermore, the model also quantifies the 5 stiffness gain extremely well for varying temperature conditions.

6

Table 5 Maturity calculations for $20^{\circ} \mathrm{C}-40^{\circ} \mathrm{C}-20^{\circ} \mathrm{C}$ sequence of curing for 50\% RAP+1\% Cement-FBM

\begin{tabular}{|c|c|c|c|c|c|c|}
\hline \multicolumn{7}{|c|}{ Curing sequence-20 ${ }^{\circ} \mathrm{C}-\mathbf{4 0}^{\circ} \mathrm{C}-\mathbf{2 0}^{\circ} \mathrm{C}$} \\
\hline $\begin{array}{c}\text { ITSM test } \\
(\mathrm{MPa})\end{array}$ & $\begin{array}{c}\text { Time } \\
\text { (days) }\end{array}$ & $\begin{array}{c}\Delta \mathrm{t} \\
(\text { days })\end{array}$ & $\begin{array}{c}\mathrm{T} \\
\left({ }^{\circ} \mathrm{C}\right)\end{array}$ & $\begin{array}{c}\Delta \mathrm{t}_{\mathrm{e}} \\
(\text { days })\end{array}$ & $\begin{array}{c}\text { Maturity } \\
\left({ }^{\circ} \mathrm{C} \text {.day) }\right.\end{array}$ & $\begin{array}{c}\text { ITSM-Predicted } \\
(\mathrm{MPa})\end{array}$ \\
\hline 1880 & 4 & 4 & 20 & 4 & 80 & 2152 \\
\hline 3171 & 8 & 4 & 40 & 18 & 732 & 3382 \\
\hline 3856 & 21 & 13 & 40 & 59 & 2458 & 3880 \\
\hline 4084 & 39 & 18 & 40 & 82 & 5750 & 4133 \\
\hline 4159 & 61 & 22 & 40 & 101 & 9773 & 4255 \\
\hline 4295 & 242 & 181 & 20 & 181 & 13393 & 4316 \\
\hline
\end{tabular}

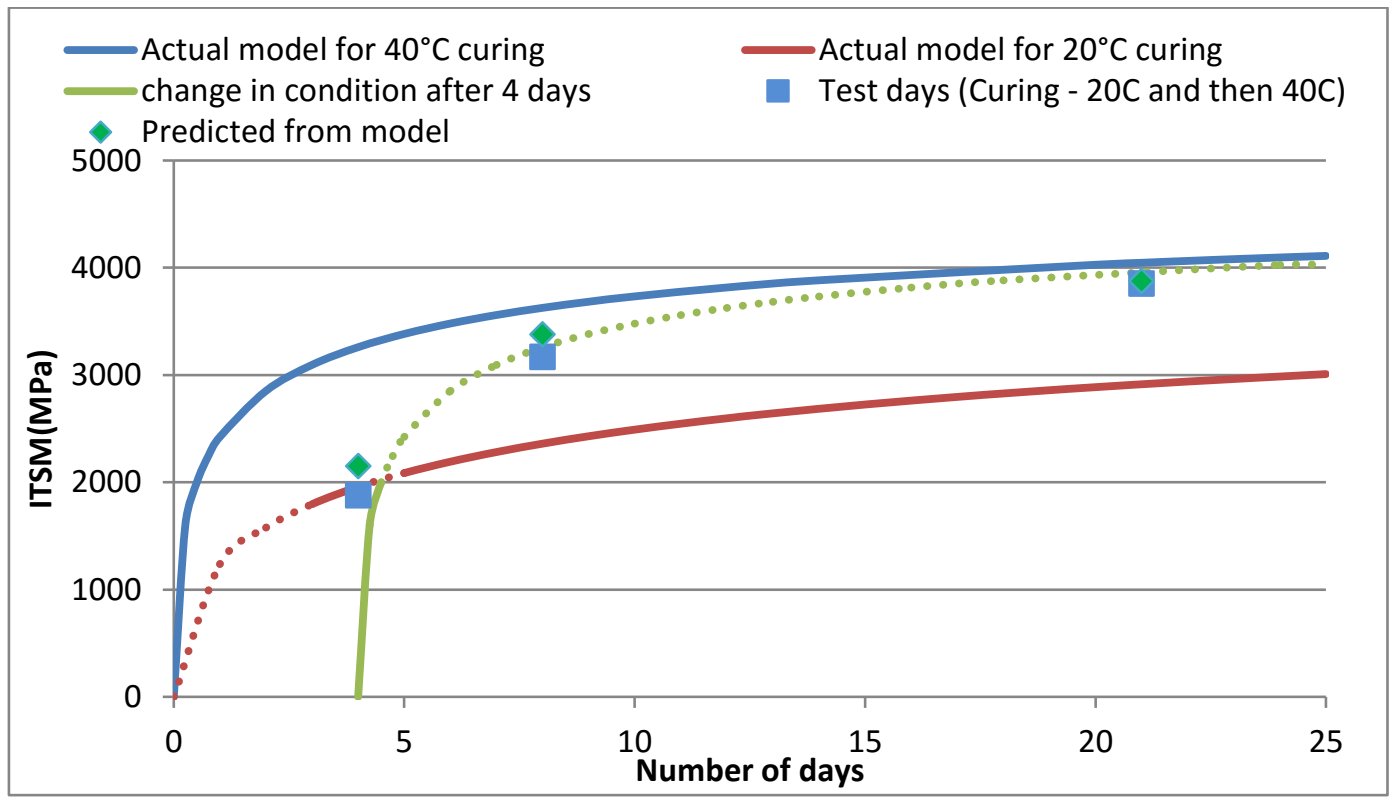

Figure 21 Effect of temperature variation on stiffness (50\%RAP + 1\% Cement)

\section{2}

\subsection{Practical implications}

As seen in the previous section the maturity method was found to be capable of estimating the stiffness under varying temperature conditions and it provides a tool to estimate in-situ stiffness after compaction of FBM layers. This method is particularly helpful to assess when the FBM layer can be covered with overlying layers if the insitu temperature data is available. To explain the applicability of the maturity method three hypothetical pavement sections were considered. The locations were selected so that each represented moderate to cold temperature so as to evaluate the effect of ambient temperature on the stiffness gain of FBM. The temperature data was obtained from the National Climatic Data Centre (NCDC) website (www.ncdc.noaa.gov). Figure 22 presents the mean daily air temperatures for April, 2014 in the locations selected. It was assumed that the construction (compaction) of the FBM layer was 
carried out on 1st of April and the mixture started gaining stiffness from the first day.

The stiffness values for each day were calculated using the cumulative maturity approach as discussed in the previous section, assuming the temperature of the FBM to be the same as the air temperature.

The stiffness results estimated using the maturity method are presented in Figure 23. For simplicity, the layer temperature was assumed to be same as the air temperature. However, for engineering purposes it is envisaged that pavement temperature models such as BELLS model could be used as an alternative. As expected the higher ambient temperatures resulted in higher stiffness values. The results show the stiffness trend for mixtures with 50\%RAP, one with $1 \%$ Cement and the other without any cement, to explain the benefit of cement addition. These trends help in taking decisions regarding when the overlying layer can be placed on the FBM layer or when the traffic can be allowed on the pavement layer. For example if an agency requirement is to place the binder course or surface course over the FBM layer only if it reaches a stiffness of $1000 \mathrm{MPa}$, in such circumstances these trends can be very helpful. Table 6 shows the effect of location and presence of cement on the number of days required to reach a stiffness of 1000MPa. As can be seen from the table both location and presence of cement significantly influence the stiffness trend and thus decisions such as trafficking and layer placements. For moderately warmer (Nottingham) and colder (Stockholm) conditions, the difference in days to reach $1000 \mathrm{MPa}$ was found to be 7 days and 9 days respectively for mixtures with cement and without cement. The influence of the cement on the early stage of curing was significant as the difference between mixtures with cement and without cement for the colder condition (Stockholm) considered in the present study was as high as 13 days.

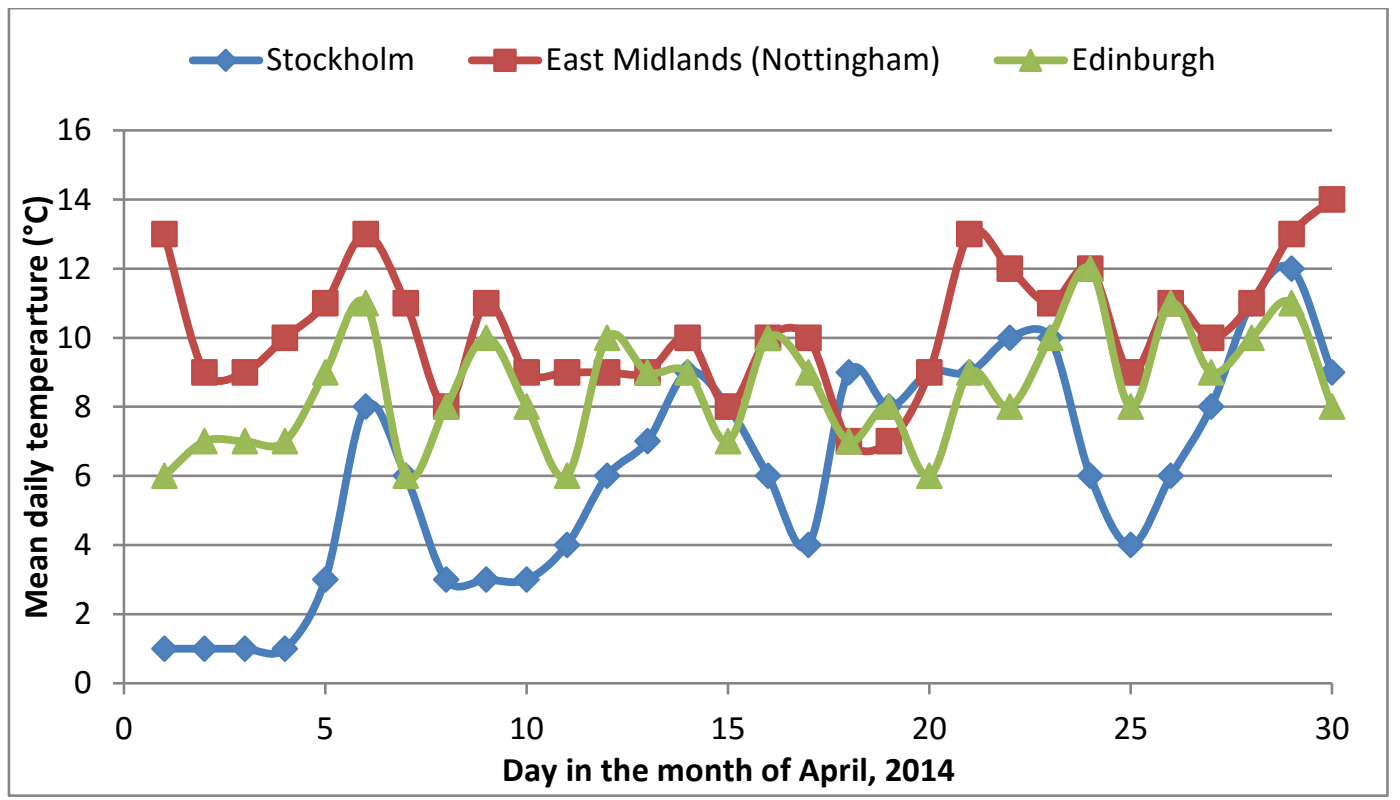

27 Figure 22 Mean daily temperatures for month of April, 2014 in locations considered in 28 the study 


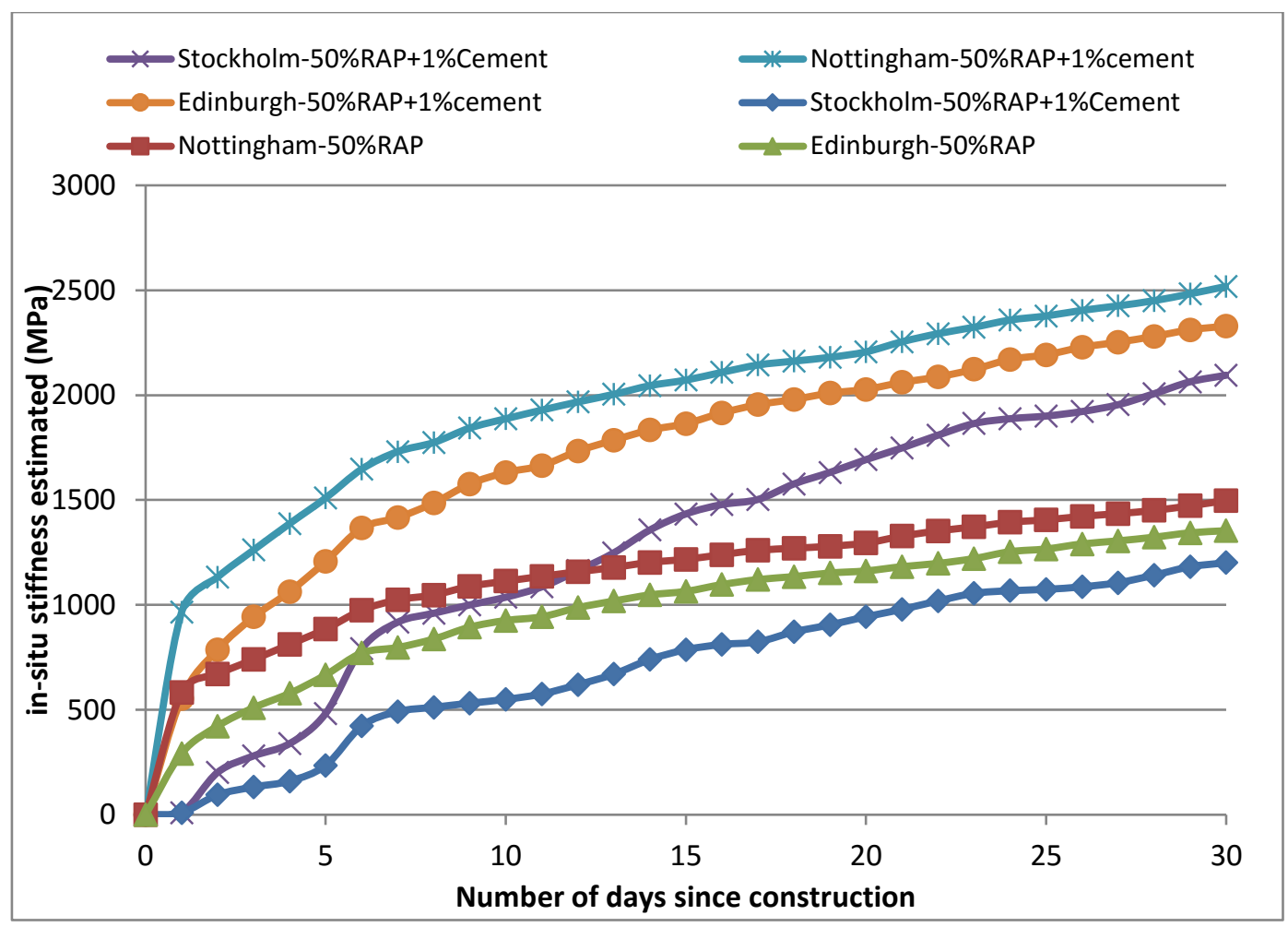

Figure 23 Effect of location and cement on stiffness gain (hypothetical sections)

4 Table 6 Practical implication of maturity method

\begin{tabular}{|c|c|c|c|}
\hline \multicolumn{4}{|c|}{ Number of days to reach stiffness of 1000 MPa } \\
\hline & Stockholm & Edinburgh & Nottingham \\
\hline 50\%RAP + 1\% Cement & 9 & 4 & 2 \\
\hline 50\% RAP & 22 & 13 & 7 \\
\hline
\end{tabular}

It has been shown in the present paper that the maturity model which describes the combined effect of time and temperature on curing can be used as an alternative to insitu water content specification to decide when a FBM layer can be overlaid with subsequent pavement layers. However, in addition to time and temperature, relative humidity and amount of rainfall are also important parameters that influence in-situ curing. Therefore, it is advised that decisions should be made in conjunction with relative humidity and precipitation data. It is also important to note that integrating the effect of traffic load on the stiffness evolution into the maturity model was not in the scope of the present paper. Clearly early-life trafficking has the potential to cause irreversible damage and this should therefore ideally be incorporated into any decision-making approach. 


\section{CONCLUSIONS}

This study was intended to improve understanding of the curing mechanism of FBMs and to lessen the gap between laboratory curing and field evolution of these mixtures. In achieving this, a link was established between laboratory mix design and field performance by evaluating applicability of the maturity method.

The study also aimed to understand the curing mechanism and to interpret the level of impact that factors such as temperature and time have on the curing of FBMs. The effect of these factors on curing was evaluated with reference to stiffness gain and water loss of specimens made from these mixtures. The following observations were made:

- The temperature is as important a parameter as time, as temperature has a greater influence on curing rate and also on bitumen properties.

- Higher curing temperatures resulted in higher rate of stiffness gain. This trend is not only because of rapid water loss but also due to an increase in binder stiffness at higher curing temperatures.

The study also evaluated the applicability of the maturity method as a tool to assess the insitu characteristics of FBM layers in the pavement. It was found that replacing the time term with an equivalent age term in the maturity function aided in estimating stiffness rather than relative stiffness. This was possible because of the characteristic curing of FBMs in which the limiting stiffness that these mixtures reach strongly depends on the curing temperature at least for the length of curing stages considered in the present study. A strong correlation was found between maturity and the stiffness values obtained from the laboratory tests which resulted in development of maturity-stiffness relationships. The application of the method to assess the insitu stiffness was presented using three hypothetical pavement sections. The results showed the influence of ambient temperature and the importance of cement addition to FBMs.

\section{REFERENCES}

1. Jenkins, K.J., \& Moloto, P. K. , Technical memorandum: Updating bituminous stabilized materials guidelines: Mix design report (Phase II Task 8: Curing Protocol: Validation). 2008, Asphalt Academy: Pretoria.

2. Batista, F.A., De Lurdes Antunes, M., Mollenhauer, K., \& McNally, C.. and I. Building blocks for a best practice guide on cold in place recycling. in 5th Eurasphalt \& Eurobitume Congress. 2012. stanbul, Turkey.

3. Lee, D.Y. Treating marginal aggregates and soil with foamed asphalt. in Association of Asphalt Paving Technologists. 1981.

4. Kim, Y., S. Im, and H.D. Lee, Impacts of Curing Time and Moisture Content on Engineering Properties of Cold In-Place Recycling Mixtures Using Foamed or Emulsified Asphalt. Journal of Materials in Civil Engineering, 2011. 23(5).

5. Tebaldi, G., et al., Synthesis of standards and procedures for specimen preparation and in-field evaluation of cold-recycled asphalt mixtures. Road Materials and Pavement Design, 2014. 15(2): p. 272-299.

6. Kuna, K., G. Airey, and N. Thom, Laboratory Mix Design Procedure for Foamed Bitumen Mixtures. 2014: Transportation Research Record: Journal of the Transportation Research Board. p. 1-10. 
7. Ojum, C., et al., An Investigation into the Effects of Accelerated Curing on Cold Recycled Bituminous Mixtures, in International Symposium of Asphalt Pavements. 2014: Raleigh, North Carolina. p. 1177-1188.

8. Leech, D., Cold mix bituminous materials for use in structural layers of roads. Crowthorne (Berkshire, UK): ;, in Transport Research Laboratory (TRL). 1994.

9. Doyle, T.A., et al., Developing maturity methods for the assessment of cold-mix bituminous materials. Construction and Building Materials, 2013. 38(0): p. 524-529.

10. Carino, N.J. and H.S. Lew, The Maturity Method: From Theory to Application. 2001, Building and Fire Research Laboratory National Institute of Standards and Technology: Gaithersburg,USA.

11. Nixon, J.M., et al., Evaluation of the Maturity Method to Estimate Concrete Strength in Field Applications, in ALDOT Research Project 930-590. 2008, Highway Research Center and Department of Civil Engineering at Auburn University.

12. Thomas A. Doyle, C.M., Amanda Gibney, Amir Tabakovic, Developing maturity methods for the assessment of cold-mix bituminous materials. Construction and Building Materials, 2013. Volume 38: p. 524-529.

13. Malhotra, V.M. and N.J. Carino, Handbook on Nondestructive Testing of Concrete Second Edition. 2003: CRC Press; 2 edition.

14. Hansen, P.F. and E.J. Pedersen, Maturity Computer for Controlled Curing and Hardening of Concrete. 1977, Swedish National Road and Transport Research Institute (VTI). p. 21-25.

15. Carino, N.J., L.I. Knab, and J.R. Clifton, Applicability of the Maturity Method to HighPerformance Concrete, in NISTIR-4819. 1992, National Institute of Standards and Technology (US): Springfield, VA.

16. Academy, A., A Guideline for the Design and Construction of Bitumen Emulsion and Foamed Bitumen Stabilised Materials. 2009.

17. J. -P. Serfass, J.-E.P., J. -P. Henrat, X. Carbonneau, Influence of curing on cold mix mechanical performance. Materials and Structures, 2004. 37(5): p. 365-368.

18. Carino, N., The Maturity Method: Theory and Application. ASTM Journal of Cement, Concrete and Aggregates, 1984. 6(2). 